NBER WORKING PAPER SERIES

\title{
MOMENTUM CRASHES
}

\author{
Kent Daniel \\ Tobias J. Moskowitz \\ Working Paper 20439 \\ http://www.nber.org/papers/w20439
}

\author{
NATIONAL BUREAU OF ECONOMIC RESEARCH \\ 1050 Massachusetts Avenue \\ Cambridge, MA 02138 \\ August 2014
}

For helpful comments and discussions, we thank Cliff Asness, John Cochrane, Pierre Collin-Dufresne, Eugene Fama, Andrea Frazzini, Gur Huberman, Ronen Israel, Mike Johannes, John Liew, Lasse Pedersen, Tano Santos, Paul Tetlock, Sheridan Titman, Narasimhan Jegadeesh, Will Goetzmann, an anonymous referee, and participants of the NBER Asset Pricing Summer Institute, the Quantitative Trading \& Asset Management Conference at Columbia, the 5-Star Conference at NYU, and seminars at Columbia, Rutgers, University of Texas at Austin, USC, Yale, Aalto, BI Norwegian Business School, Copenhagen Business School, Swiss Finance Institute, the Q group, Kepos Capital, and SAC. Moskowitz has an ongoing relationship with AQR Capital, who invests in, among many other things, momentum strategies. The views expressed herein are those of the authors and do not necessarily reflect the views of the National Bureau of Economic Research.

At least one co-author has disclosed a financial relationship of potential relevance for this research. Further information is available online at http://www.nber.org/papers/w20439.ack

NBER working papers are circulated for discussion and comment purposes. They have not been peerreviewed or been subject to the review by the NBER Board of Directors that accompanies official NBER publications.

(C) 2014 by Kent Daniel and Tobias J. Moskowitz. All rights reserved. Short sections of text, not to exceed two paragraphs, may be quoted without explicit permission provided that full credit, including (C) notice, is given to the source. 
Momentum Crashes

Kent Daniel and Tobias J. Moskowitz

NBER Working Paper No. 20439

August 2014

JEL No. G11,G12

\begin{abstract}
$\underline{\text { ABSTRACT }}$
Despite their strong positive average returns across numerous asset classes, momentum strategies can experience infrequent and persistent strings of negative returns. These momentum crashes are partly forecastable. They occur in "panic" states - following market declines and when market volatility is high - and are contemporaneous with market rebounds. We show that the low ex-ante expected returns in panic states are consistent with a conditionally high premium attached to the option-like payoffs of past losers. An implementable dynamic momentum strategy based on forecasts of momentum's mean and variance approximately doubles the alpha and Sharpe Ratio of a static momentum strategy, and is not explained by other factors. These results are robust across multiple time periods, international equity markets, and other asset classes.
\end{abstract}

Kent Daniel

Graduate School of Business

Columbia University

3022 Broadway, Uris Hall 421

New York, NY 10027

and NBER

kd2371@columbia.edu

Tobias J. Moskowitz

Booth School of Business

University of Chicago

5807 S. Woodlawn Ave.

Chicago, IL 60637

and NBER

tobias.moskowitz@ chicagobooth.edu 


\section{Introduction}

A momentum strategy is a bet on past returns predicting the cross-section of future returns, typically implemented by buying past winners and selling past losers. Momentum is pervasive: the academic literature documents the efficacy of momentum strategies across multiple time periods, many markets, and in numerous asset classes. $^{1}$

However, the strong positive average returns and Sharpe ratios of momentum strategies are punctuated with occasional "crashes." Like the returns to the carry trade in currencies (e.g., Brunnermeier, Nagel, and Pedersen (2008)), momentum returns are negatively skewed, and the negative returns can be pronounced and persistent. In our 1927 to 2013 U.S. equity sample, the two worst months for a momentum strategy that buys the top decile of past 12-month winners and shorts the bottom decile of losers are consecutive: July and August of 1932. Over this short period, the past-loser decile portfolio returned $232 \%$, while the past-winner decile portfolio had a gain of only $32 \%$. In a more recent crash, over the three-month period from March to May of 2009, the past-loser decile rose by $163 \%$, while the decile portfolio of past winners gained only $8 \%$.

We investigate the impact and potential predictability of these momentum crashes, which appear to be a key and robust feature of momentum strategies. We find that crashes tend to occur in times of market stress, when the market has fallen and ex-ante measures of volatility are high, coupled with an abrupt rise in contemporaneous market returns.

Our result is consistent with that of Cooper, Gutierrez, and Hameed (2004) and Stivers and Sun (2010), who find, respectively, that the momentum premium falls when the past threeyear market return has been negative and that the momentum premium is low when market

\footnotetext{
${ }^{1}$ Momentum strategies were first documented in U.S. common stock returns from 1965 to 1989 by Jegadeesh and Titman (1993) and Asness (1994), by sorting firms on the basis of three to 12 month past returns. Subsequently, Jegadeesh and Titman (2001) show the continuing efficacy of US equity momentum portfolios in common stock returns in the 1990 to 1998 period. Israel and Moskowitz (2013) show the robustness of momentum prior to and after these studies from 1927 to 1965 and from 1990 to 2012. There is evidence of momentum going back to the Victorian age from Chabot, Remy, and Jagannathan (2009) and evidence from 1801 to 2012 from Geczy and Samonov (2013) in what the authors call "the world's longest backtest." Moskowitz and Grinblatt (1999) find momentum in industry portfolios. Rouwenhorst (1998) and Rouwenhorst (1999) finds momentum in developed and emerging equity markets, respectively. Asness, Liew, and Stevens (1997) find momentum in country indices. Okunev and White (2003) find momentum in currencies; Erb and Harvey (2006) in commodities; Moskowitz, Ooi, and Pedersen (2012) in exchange traded futures contracts; and Asness, Moskowitz, and Pedersen (2013), who integrate this evidence across markets and asset classes, find momentum in bonds as well.
} 
volatility is high. Cooper, Gutierrez, and Hameed (2004) offer a behavioral explanation for these facts that may also be consistent with momentum performing particularly poorly during market rebounds if those are also times when assets become more mispriced. However, we investigate another source for these crashes by examining conditional risk measures.

In particular, the patterns we find are suggestive of the changing beta of the momentum portfolio partly driving the momentum crashes. The time variation in betas of return sorted portfolios was first documented by Kothari and Shanken (1992), who argue that, by their nature, past-return sorted portfolios will have significant time-varying exposure to systematic factors. Because momentum strategies are long/overweight (short/underweight) past winners (losers), they will have positive loadings on factors which have had a positive realization over the formation period of the momentum strategy.

Grundy and Martin (2001) apply Kothari and Shanken's insights to price momentum strategies. Intuitively, the result is straightforward, if not often appreciated: when the market has fallen significantly over the momentum formation period - in our case from 12 months ago to one month ago - there is a good chance that the firms that fell in tandem with the market were and are high beta firms, and those that performed the best were low beta firms. Thus, following market declines, the momentum portfolio is likely to be long low-beta stocks (the past winners), and short high-beta stocks (the past losers). We verify empirically that there is dramatic time variation in the betas of momentum portfolios. We find that, following major market declines, betas for the past-loser decile can rise above 3 , and fall below 0.5 for past winners. Hence, when the market rebounds quickly, momentum strategies will crash because they have a conditionally large negative beta.

Grundy and Martin (2001) argue that performance of momentum strategies is dramatically improved, particularly in the pre-WWII era, by dynamically hedging market and size risk. However, their hedged portfolio is constructed based on forward-looking betas, and is therefore not an implementable strategy. We show that this results in a strong bias in estimated returns, and that a hedging strategy based on ex-ante betas does not exhibit the performance improvement noted in Grundy and Martin (2001).

The source of the bias is a striking correlation of the loser-portfolio beta with the return on the market. Using a Henriksson and Merton (1981) specification, we calculate up- and downbetas for the momentum portfolios and show that, in a bear market, a momentum portfolio's 
up-market beta is more than double its down-market beta $(-1.51$ versus -0.70 with a $t$-stat of the difference $=4.5$ ). Outside of bear markets, there is no statistically reliable difference in betas.

More detailed analysis reveals that most of the up- versus down-beta asymmetry in bear markets is driven by the past losers. This pattern in dynamic betas of the loser portfolio implies that momentum strategies in bear markets behave like written call options on the market - when the market falls, they gain a little, but when the market rises they lose a lot.

Consistent with the written call option-like behavior of the momentum strategy in bear markets, we show that time variation in the momentum premium is related to time-varying exposure to volatility risk. Using VIX-imputed variance-swap returns, we find that the payoffs to momentum strategies have a strong negative exposure to innovations in market variance in bear markets, but not in "normal" markets. However, we also show that hedging out this time varying exposure to market variance (by buying S\&P variance swaps in bear markets, for instance) does not restore the profitability of momentum in bear markets. Hence, time varying exposure to volatility risk is only a partial explanation.

Using the insights from the relationship between momentum payoffs and volatility, and the fact that the momentum strategy volatility is itself predictable and distinct from the predictability in its mean return, we design an optimal dynamic momentum strategy which is levered up or down over time so as to maximize the unconditional Sharpe ratio of the portfolio. We first show theoretically that, to maximize the unconditional Sharpe ratio, a dynamic strategy should scale the weights, at each point in time, so that the dynamic strategy's conditional volatility is proportional to the conditional Sharpe ratio of the strategy. Then, using the insights from our analysis on the forecastability of both the momentum premium and momentum volatility, we estimate these conditional moments to generate the dynamic weights.

We find that the optimal dynamic strategy significantly outperforms the standard static momentum strategy, more than doubling its Sharpe ratio and delivering significant positive alpha relative to the market, Fama and French factors, the static momentum portfolio and conditional versions of all of these models that allow betas to vary in the crash states. In addition, the dynamic momentum strategy also significantly outperforms constant volatility momentum strategies suggested in the literature (e.g., Barroso and Santa-Clara (2012)), producing positive alpha relative to the constant volatility strategy and capturing the constant volatil- 
ity strategy's returns in spanning tests. The dynamic strategy not only helps smooth the volatility of momentum portfolios, as does the constant volatility approach, but in addition also exploits the strong forecastability of the momentum premium, which we uncover in our analysis of the option-like payoffs of losers in bear markets.

Given the paucity of momentum crashes and the pernicious effects of data mining from an ever-expanding search across studies (and in practice) for strategies that improve performance, we challenge the robustness of our findings by replicating the results in different sample periods, four different equity markets, and five distinct asset classes. Across different time periods, markets, and asset classes, we find remarkably consistent results. First, the results are robust in every quarter-century subsample in US equities. Second, we show that momentum strategies in all markets and asset classes suffer from crashes, which are consistently driven by the conditional beta and option-like feature of losers. The same option-like behavior of losers in bear markets is present in Europe, Japan, the UK, globally, and is a feature of index futures-, commodity-, fixed income-, and currency-momentum strategies. Third, the same dynamic momentum strategy applied in these alternative markets and asset classes is ubiquitously successful in generating superior performance over the static and constant volatility momentum strategies in each market and asset class. The additional improvement from dynamic weighting is large enough to produce significant momentum profits even in markets where the static momentum strategy has famously failed to yield positive profits - e.g., Japan. Taken together, and applied across all markets and asset classes, a dynamic momentum strategy delivers an annualized Sharpe ratio of 1.18, which is four times larger than that of the static momentum strategy applied to US equities over the same period, and thus posing an even greater challenge for rational asset pricing models (Hansen and Jagannathan 1991).

Finally, we consider several possible explanations for the option-like behavior of momentum payoffs, particularly for losers. For equity momentum strategies, one possibility is that the optionality arises because a share of common stock is a call option on the underlying firm's assets when there is debt in the capital structure (Merton 1974). Particularly in distressed periods where this option-like behavior is manifested, the underlying firm values among past losers have generally suffered severely, and are therefore potentially much closer to a level where the option convexity is strong. The past winners, in contrast, would not have suffered the same losses, and may still be "in-the-money." While this explanation seems to have merit for equity momentum portfolios, this hypothesis does not seem applicable for index future, commodity, fixed income, and currency momentum, which also exhibit strong option-like 
behavior. In the conclusion, we briefly discuss a behaviorally motivated explanation for these option-like features that could apply to all asset classes, but a fuller understanding of these convex payoffs is an open area for future research.

The layout of the paper is as follows: Section 2 describes the data and portfolio construction and dissects momentum crashes in US equities. Section 3 measures the conditional betas and option-like payoffs of losers and assesses to what extent these crashes are predictable based on these insights. Section 4 examines the performance of an optimal dynamic strategy based on our findings, and whether its performance can be explained by dynamic loadings on other known factors or other momentum strategies proposed in the literature. Section 5 examines the robustness of our findings in different time periods, international equity markets, and other asset classes. Section 6 concludes by speculating about the sources of the premia we observe and discusses areas for future research.

\section{US Equity Momentum}

In this section, we present the results of our analysis of momentum in US common stocks over the 1927 to 2013 time period. We begin with the data description and portfolio construction.

\subsection{US Equity Data and Momentum Portfolio Construction}

Our principal data source is the Center for Research in Security Prices (CRSP). We construct monthly and daily momentum decile portfolios, where both sets of portfolios are rebalanced at the end of each month. The universe starts with all firms listed on NYSE, AMEX or NASDAQ as of the formation date, using only the returns of common shares (with CRSP sharecode of 10 or 11). We require that a firm have a valid share price and number of shares as of the formation date, and that there be a minimum of eight monthly returns over the past 11 months, skipping the most recent month, which is our formation period. Following

convention and CRSP availability, all prices are closing prices, and all returns are from close to close.

To form the momentum portfolios, we first rank stocks based on their cumulative returns from 12 months before to one month before the formation date (e.g., $t-12$ to $t-2$ ), where, 


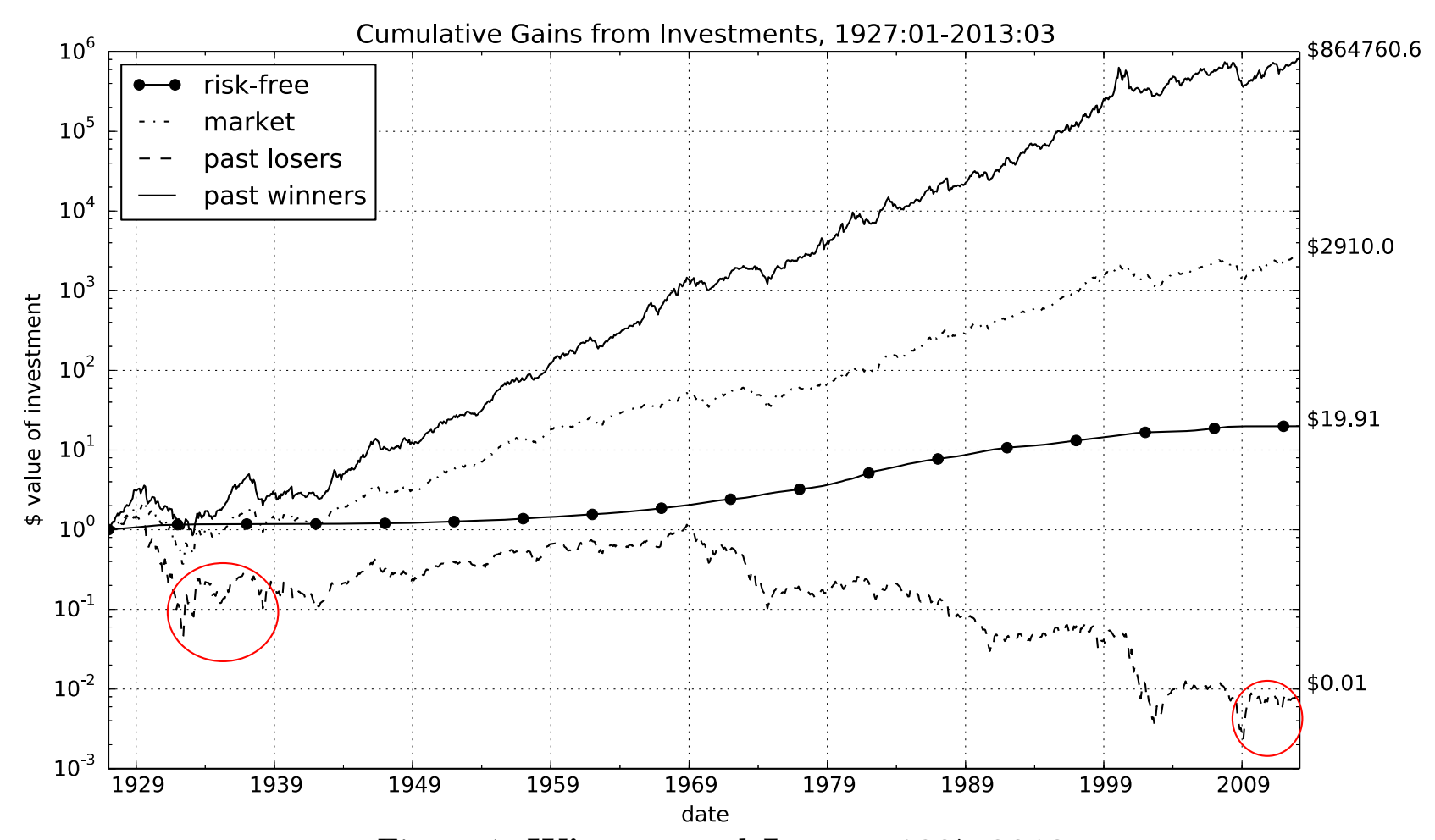

Figure 1: Winners and Losers, 1927-2013

Plotted are the cumulative returns for four assets: (1) the risk-free asset; (2) the CRSP value-weighted index; (3) the bottom decile "past loser" portfolio; and (4) the top decile "past winner" portfolio over the full sample period 1927:01 to 2013:03. On the right side of the plot the final dollar values for each of the four portfolios, given a $\$ 1$ investment in January 1927, are reported.

consistent with the literature (Jegadeesh and Titman (1993), Asness (1994), Fama and French (1996)), we use a one month gap between the end of the ranking period and the start of the holding period to avoid the short-term one-month reversals documented by Jegadeesh (1990) and Lehmann (1990). All firms meeting the data requirements are then placed into one of ten decile portfolios based on this ranking, where portfolio 10 represents the "Winners" (those with the highest past returns) and portfolio 1 the "Losers," and the value-weighted holding period returns of the decile portfolios are computed, where portfolio membership does not change within a month, except in the case of delisting.

The market return is the value weighted index of all listed firms in CRSP and the risk free rate series is the one-month Treasury bill rate, both obtained from Ken French's data library. We convert the monthly risk-free rate series to a daily series by converting the risk-free rate at the beginning of each month to a daily rate, and assuming that that daily rate is valid throughout the month. 
Table 1: Momentum Portfolio Characteristics, 1927:01-2013:03

This table presents characteristics of the monthly momentum decile portfolio excess returns over the 87 year full sample period from 1927:01-2013:03. Decile 1 represents the biggest losers and decile 10 the biggest winners, with WML representing the zero-cost winners minus losers portfolio. The mean excess return, standard deviation, and alpha are in percent, and annualized. The Sharpe ratio is annualized. The $\alpha, t(\alpha)$, and $\beta$ are estimated from a full-period regression of each decile portfolio's excess return on the excess CRSP-value weighted index. For all portfolios except WML, SK $(\mathrm{m})$ denotes the full-period realized skewness of the monthly $\log$ returns (not excess) to the portfolios and SK(d) denotes the full-period realized skewness of the daily log returns. For WML, SK is the realized skewness of $\log \left(1+r_{\mathrm{WML}}+r_{f}\right)$.

\begin{tabular}{|c|c|c|c|c|c|c|c|c|c|c|c|c|}
\hline & \multicolumn{10}{|c|}{ Momentum Decile Portfolios } & \multirow[b]{2}{*}{ wml } & \multirow[b]{2}{*}{ Mkt } \\
\hline & 1 & 2 & 3 & 4 & 5 & 6 & 7 & 8 & 9 & 10 & & \\
\hline$\overline{r-r_{f}}$ & -2.5 & 2.9 & 2.9 & 6.4 & 7.1 & 7.1 & 9.2 & 10.4 & 11.3 & 15.3 & 17.9 & 7.7 \\
\hline$\sigma$ & 36.5 & 30.5 & 25.9 & 23.2 & 21.3 & 20.2 & 19.5 & 19.0 & 20.3 & 23.7 & 30.0 & 18.8 \\
\hline$\alpha$ & -14.7 & -7.8 & -6.4 & -2.1 & -0.9 & -0.6 & 1.8 & 3.2 & 3.8 & 7.5 & 22.2 & 0 \\
\hline$t(\alpha)$ & $(-6.7)$ & $(-4.7)$ & $(-5.3)$ & $(-2.1)$ & $(-1.1)$ & $(-1.0)$ & $(2.8)$ & $(4.5)$ & $(4.3)$ & $(5.1)$ & $(7.3)$ & (0) \\
\hline$\beta$ & 1.61 & 1.41 & 1.23 & 1.13 & 1.05 & 1.02 & 0.98 & 0.95 & 0.99 & 1.03 & -0.58 & 1 \\
\hline SR & -0.07 & 0.09 & 0.11 & 0.28 & 0.33 & 0.35 & 0.47 & 0.54 & 0.56 & 0.65 & 0.60 & 0.41 \\
\hline $\mathrm{SK}(\mathrm{m})$ & 0.09 & -0.05 & -0.19 & 0.21 & -0.13 & -0.30 & -0.55 & -0.54 & -0.76 & -0.82 & -4.70 & -0.57 \\
\hline $\mathrm{SK}(\mathrm{d})$ & 0.12 & 0.29 & 0.22 & 0.27 & 0.10 & -0.10 & -0.44 & -0.66 & -0.67 & -0.61 & -1.18 & -0.44 \\
\hline
\end{tabular}

\subsection{Momentum Portfolio Performance}

Figure 1 presents the cumulative monthly returns from 1927:01-2013:03 for investments in: (1) the risk-free asset; (2) the market portfolio; (3) the bottom decile "past loser" portfolio; and (4) the top decile "past winner" portfolio. On the right side of the plot, we present the final dollar values for each of the four portfolios, given a \$1 investment in January, 1927 (and, of course, assuming no transaction costs).

Consistent with the existing literature, there is a strong momentum premium over the last century. The winners significantly outperform the losers and by much more than equities have outperformed Treasuries. Table 1 presents return moments for the momentum decile portfolios over this period. The winner decile excess return averages $15.3 \%$ per year, and the loser portfolio averages $-2.5 \%$ per year. In contrast the average excess market return is $7.6 \%$. The Sharpe ratio of the WML portfolio is 0.71 , and that of the market is 0.40 . Over this period, the beta of the WML portfolio is negative, -0.58 , giving it an unconditional CAPM alpha of $22.3 \%$ per year $(t$-stat $=8.5)$. Given the high alpha, an ex-post optimal combination of the market and WML portfolio has a Sharpe ratio more than double that of the market. 


\subsection{Momentum Crashes}

Despite the fact that the momentum strategy generates substantial profits over time, since 1927 there have been a number of long periods over which momentum under-performed dramatically. Figure 1 highlights two momentum "crashes" in particular: June 1932 to December 1939 and more recently March 2009 to March 2013. These two periods represent the two largest and sustained drawdown periods for the momentum strategy and are selected purposely to illustrate the crashes we study more generally in this paper. The starting dates for these two periods are not selected randomly: March 2009 and June 1932 are, respectively, the "market bottoms" following the stock market decline associated with the recent financial crisis, and with the market decline preceding the great depression.

Zeroing in on these crash periods, Figure 2 shows the cumulative daily returns to the same set of portfolios from Figure 1 - risk-free, market, past losers, past winners - over these subsamples. Over both of these periods, the loser portfolio strongly outperforms the winner portfolio. From March 8, 2009 to March 28, 2013, the losers produce more than twice the profits of the winners, which also underperform the market over this period. From June 1, 1932 to December 30, 1939 the losers outperform the winners by 50 percent.

Table 1 also shows that the winner portfolios are considerably more negatively skewed (monthly and daily) than the loser portfolios. While the winners still outperform the losers over time, the Sharpe ratio and alpha understate the significance of these crashes. Looking at the skewness of the portfolios, winners become more negatively skewed moving to more extreme deciles. For the top winner decile portfolio, the monthly (daily) skewness is $-0.82(-0.61)$, while for the most extreme bottom decile of losers the skewness is 0.09 (0.12). The WML portfolio over this full sample period has a monthly (daily) skewness of $-4.70(-1.18)$.

Table 2 presents the worst monthly returns to the WML strategy, as well as the lagged twoyear returns on the market, and the contemporaneous monthly market return. Several key points emerge from Table 2 as well as from Figures 1 and 2:

1. While past winners have generally outperformed past losers, there are relatively long periods over which momentum experiences severe losses or "crashes."

2. Fourteen of the 15 worst momentum returns occur when the lagged two-year market return is negative. All occur in months where the market rose contemporaneously, often in a dramatic fashion. 
Cumulative Gains from Investments, Mar 09, 2009 - Mar 28, 2013

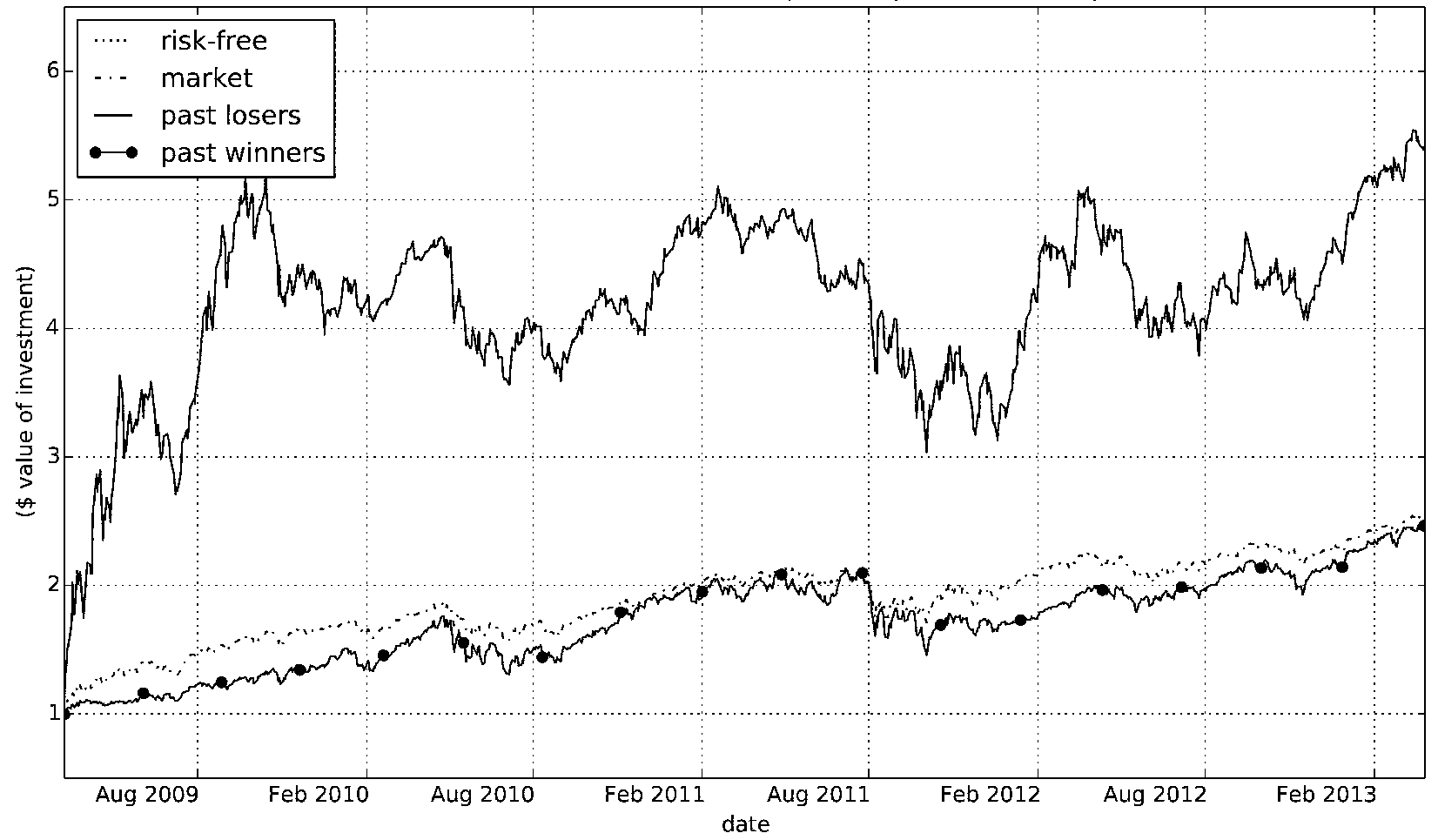

Cumulative Gains from Investments, Jun 01, 1932 - Dec 30, 1939

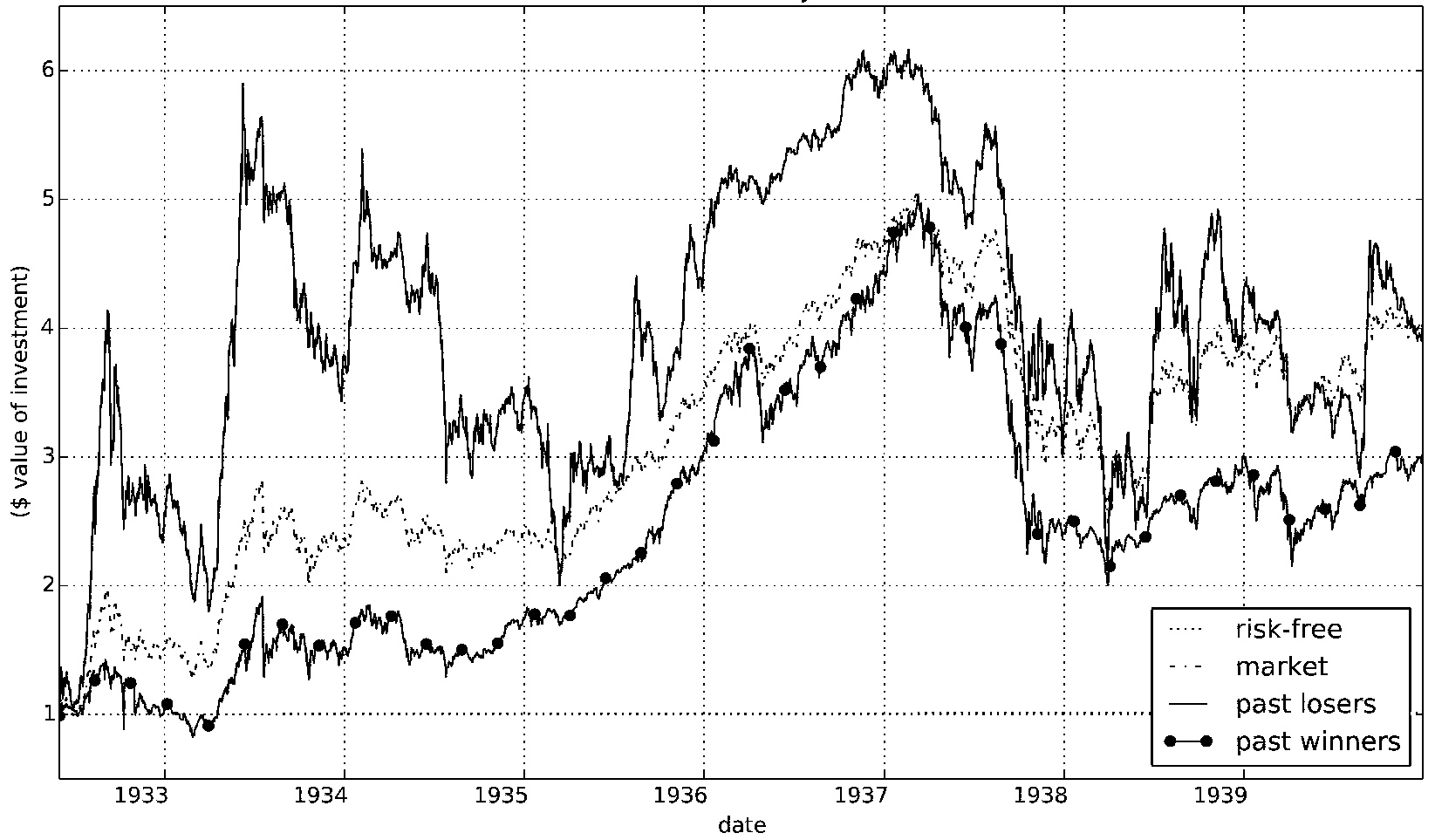

Figure 2: Momentum Crashes, Following the Great Depression and the 2008-09

Financial Crisis

Plotted are the cumulative daily returns to four portfolios: (1) the risk-free asset; (2) the CRSP value-weighted index; (3) the bottom decile "past loser" portfolio; and (4) the top decile "past winner" portfolio over the period from March 8, 2009 through March, 282013 (top graph) and from June 1, 1932 through December 30, 1939 (bottom graph). 
3. The clustering evident in this table, and the daily cumulative returns in Figure 2, make clear that the crashes have relatively long duration. They do not occur over the span of minutes or days - a crash is not a Poisson jump. They take place slowly, over the span of multiple months.

4. Similarly, the extreme losses are clustered: The two worst months for momentum are back-to-back, in July and August of 1932, following a market decline of roughly $90 \%$ from the 1929 peak. March and April of 2009 are the 7th and 4th worst momentum months, respectively, and April and May of 1933 are the 6th and 12th worst. Three of the ten worst momentum monthly returns are from 2009 - a three-month period in which the market rose dramatically and volatility fell. While it might not seem surprising that the most extreme returns occur in periods of high volatility, the effect is asymmetric for losses versus gains: the extreme momentum gains are not nearly as large in magnitude, or as concentrated in time.

5. Closer examination reveals that the crash performance is mostly attributable to the short side or the performance of losers. For example, in July and August of 1932, the market actually rose by $82 \%$. Over these two months, the winner decile rose by $32 \%$, but the loser decile was up by $232 \%$. Similarly, over the three month period from March to May of 2009 , the market was up by $26 \%$, but the loser decile was up by $163 \%$. Thus, to the extent that the strong momentum reversals we observe in the data can be characterized as a crash, they are a crash where the short side of the portfolio - the losers - are "crashing up" rather than down.

Table 2 also suggests that large changes in market beta may help to explain some of the large negative returns earned by momentum strategies. For example, as of the beginning of March 2009, the firms in the loser decile portfolio were, on average, down from their peak by $84 \%$. These firms included those hit hardest by the financial crisis: Citigroup, Bank of America, Ford, GM, and International Paper (which was highly levered). In contrast, the past-winner portfolio was composed of defensive or counter-cyclical firms like Autozone. The loser firms, in particular, were often extremely levered, and at risk of bankruptcy. In the sense of the Merton (1974) model, their common stock was effectively an out-of-the-money option on the underlying firm value. This suggests that there were potentially large differences in the market betas of the winner and loser portfolios that generate convex, option-like payoffs - a conjecture we now investigate more formally in the next section. 

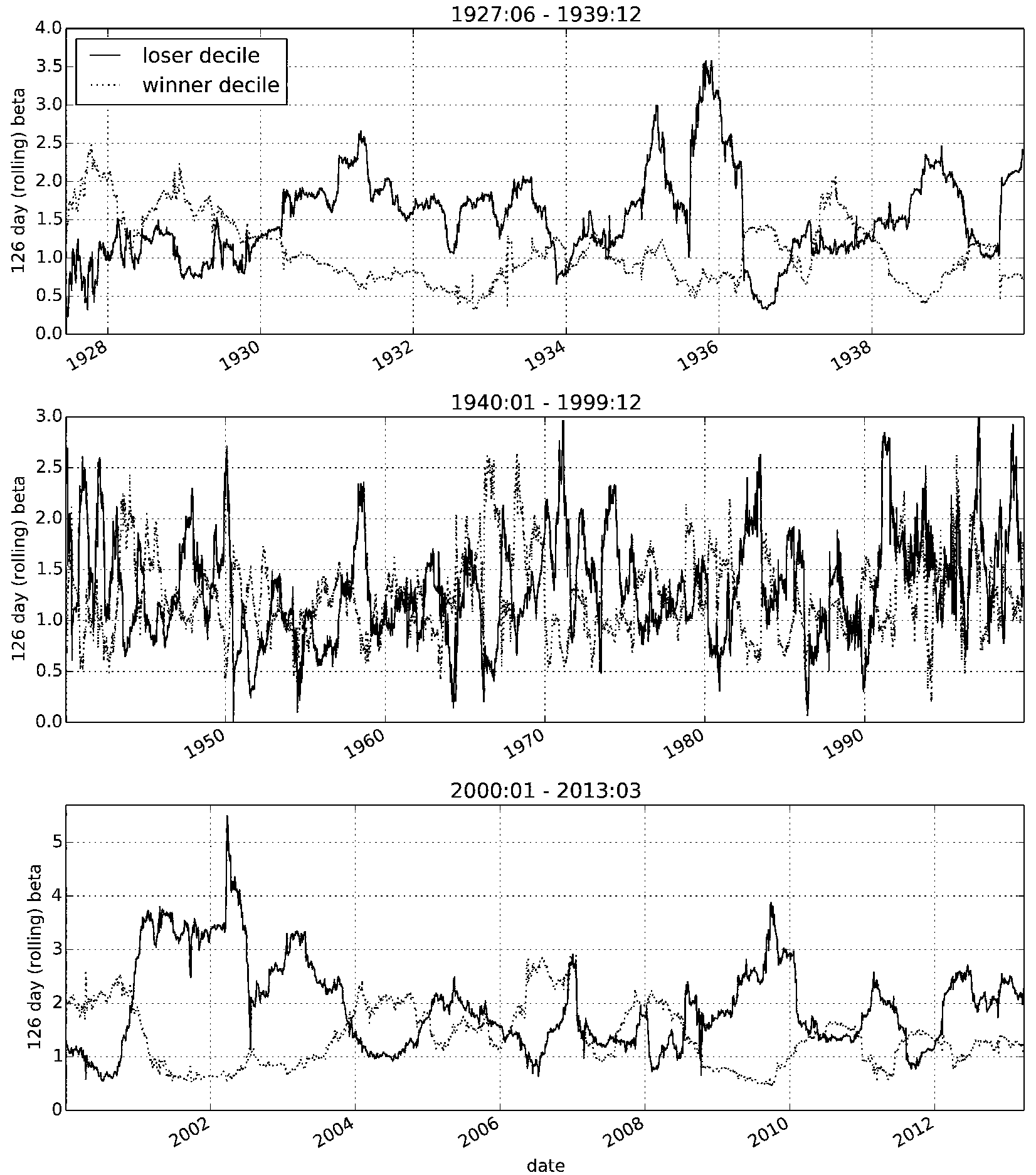

Figure 3: Market Betas of Winner and Loser Decile Portfolios

These three plots present the estimated market betas over three independent subsamples spanning our full sample: 1927:06 to 1939:12, 1940:01 to 1999:12, and 2000:01 to 2013:03. The betas are estimated by running a set of 126-day rolling regressions of the momentum portfolio excess returns on the contemporaneous excess market return and 10 (daily) lags of the market return, and summing the betas. 


\section{Table 2: Worst Monthly Momentum Returns}

This table lists the 15 worst monthly returns to the WML momentum portfolio over the 1927:01-2013:03 time period. Also tabulated are Mkt-2y, the 2-year market returns leading up to the portfolio formation date, and $\mathrm{Mkt}_{t}$, the contemporaneous market return. The dates between July 1932 and September 1939 are marked with *, those between April and August of 2009 with $^{\dagger}$; those from January 2001 and November 2002 with ${ }^{\ddagger}$. All numbers in the table are in percent.

\begin{tabular}{cccrr}
\hline Rank & Month & WML $_{t}$ & MKT-2y & Mkt $_{t}$ \\
\hline 1 & $1932-08^{*}$ & -74.36 & -67.77 & 36.49 \\
2 & $1932-07^{*}$ & -60.98 & -74.91 & 33.63 \\
3 & $2001-01^{\ddagger}$ & -49.19 & 10.74 & 3.66 \\
4 & $2009-04^{\dagger}$ & -45.52 & -40.62 & 10.20 \\
5 & $1939-09^{*}$ & -43.83 & -21.46 & 16.97 \\
6 & $1933-04^{*}$ & -43.14 & -59.00 & 38.14 \\
7 & $2009-03^{\dagger}$ & -42.28 & -44.90 & 8.97 \\
8 & $2002-11^{\ddagger}$ & -37.04 & -36.23 & 6.08 \\
9 & $1938-06^{*}$ & -33.36 & -27.83 & 23.72 \\
10 & $2009-08^{\dagger}$ & -30.54 & -27.33 & 3.33 \\
11 & $1931-06^{*}$ & -29.72 & -47.59 & 13.87 \\
12 & $1933-05^{*}$ & -28.90 & -37.18 & 21.42 \\
13 & $2001-11^{\ddagger}$ & -25.31 & -19.77 & 7.71 \\
14 & $2001-10^{\ddagger}$ & -24.98 & -16.77 & 2.68 \\
15 & $1974-01$ & -24.04 & -5.67 & 0.46 \\
\hline
\end{tabular}

\section{Time-Varying Beta and Option-Like Payoffs}

To investigate the time-varying betas of winners and losers, Figure 3 plots the market betas for the winner and loser momentum deciles, estimated using 126 day ( $\approx 6$ month) rolling market model regressions with daily data. ${ }^{2}$ Figure 3 plots the betas over three non-overlapping subsamples that span the full sample period: July 1927 to December 1939, January 1940 to December 1999, and January 2000 to March 2013.

The betas move around substantially, especially for the losers portfolio, whose beta tends

\footnotetext{
${ }^{2}$ We use 10 daily lags of the market return in estimating the market betas. Specifically, we estimate a daily regression specification of the form:

$$
\tilde{r}_{i, t}^{e}=\beta_{0} \tilde{r}_{m, t}^{e}+\beta_{1} \tilde{r}_{m, t-1}^{e}+\cdots+\beta_{10} \tilde{r}_{m, t-10}^{e}+\tilde{\epsilon}_{i, t}
$$

and then report the sum of the estimated coefficients $\hat{\beta}_{0}+\hat{\beta}_{1}+\cdots+\hat{\beta}_{10}$. Particularly for the past loser portfolios, and especially in the pre-WWII period, the lagged coefficients are strongly significant, suggesting that market wide information is incorporated into the prices of many of the firms in these portfolios over the span of multiple days. See Lo and MacKinlay (1990) and Jegadeesh and Titman (1995).
} 
to increase dramatically during volatile periods. The first and third plots highlight the betas several years before, during, and after the momentum crashes. The beta of the winner portfolio is sometimes above 2 following large market rises, but for the loser portfolio, the beta reaches far higher levels (as high as 4 or 5). The widening beta differences between winners and losers, coupled with the facts from Table 2 that these crash periods are characterized by sudden and dramatic market upswings, means that the WML strategy will experience huge losses during these times. We examine these patterns more formally by investigating how the mean return of the momentum portfolio is linked to time variation in market beta.

\subsection{Hedging Market Risk in the Momentum Portfolio}

Grundy and Martin (2001) explore this same question, arguing that the poor performance of the momentum portfolio in the pre-WWII period first documented by Jegadeesh and Titman (1993) is a result of time varying market and size exposure. Specifically, they argue that a hedged momentum portfolio - for which conditional market and size exposure is zero - has a high average return and a high Sharpe-ratio in the pre-WWII period when the unhedged momentum portfolio suffers.

At the time that Grundy and Martin (2001) undertook their study, daily stock return data was not available through CRSP in the pre-1962 period. Given the dynamic nature of momentum's risk-exposures, estimating the future hedge coefficients ex-ante with monthly data is problematic. As a result, Grundy and Martin (2001) use an ex-post estimate of the portfolio's market and size betas using monthly returns over the current month and the future five months.

However, to the extent that the future momentum-portfolio beta is correlated with the future return of the market, this procedure will result in a biased estimate of the returns of the hedged portfolio. We show there is in fact a strong correlation of this type, which results in a large upward bias in the estimated performance of the hedged portfolio. ${ }^{3}$

\footnotetext{
${ }^{3}$ The result that the betas of winner-minus-loser portfolios are non-linearly related to contemporaneous market returns has also been documented in Rouwenhorst (1998) who documents this feature for non-US equity momentum strategies (Table V, p. 279). Chan (1988) and DeBondt and Thaler (1987) document this non-linearity for longer-term winner/loser portfolios. However, Boguth, Carlson, Fisher, and Simutin (2010), building on the results of Jagannathan and Korajczyk (1986), note that the interpretation of the measures of abnormal performance (i.e., the alphas) in Chan (1988), Grundy and Martin (2001), and Rouwenhorst (1998) are problematic and provide a critique of Grundy and Martin (2001) and other studies which "overcondition"
} 
Table 3: Market Timing Regression Results

This table presents the results of estimating four specifications of a monthly time-series regressions run over the period 1927:01 to 2013:03. In all cases the dependent variable is the return on the WML portfolio. The independent variables are a constant, an indicator for bear markets, $I_{B, t-1}$, which equals one if the cumulative past two-year return on the market is negative, the excess market return, $R_{m, t}^{e}$, and a contemporaneous upmarket indicator, $I_{U, t}$, which equals one if $R_{m, t}^{e}>0$. The coefficients $\hat{\alpha}_{0}$ and $\hat{\alpha}_{B}$ are $\times 100$ (i.e., are in percent per month).

\begin{tabular}{|c|c|c|c|c|c|}
\hline \multirow[b]{2}{*}{ Coef. } & \multirow[b]{2}{*}{ Variable } & \multicolumn{4}{|c|}{$\begin{array}{c}\text { Estimated Coefficients } \\
\text { (t-statistics in parentheses) }\end{array}$} \\
\hline & & (1) & $(2)$ & $(3)$ & $(4)$ \\
\hline$\hat{\alpha}_{0}$ & 1 & $\begin{array}{r}1.852 \\
(7.3)\end{array}$ & $\begin{array}{r}1.976 \\
(7.7)\end{array}$ & $\begin{array}{r}1.976 \\
(7.8)\end{array}$ & $\begin{array}{r}2.030 \\
(8.4)\end{array}$ \\
\hline$\hat{\alpha}_{B}$ & $\mathrm{I}_{B, t-1}$ & & $\begin{array}{r}-2.040 \\
(-3.4)\end{array}$ & $\begin{array}{r}0.583 \\
(0.7)\end{array}$ & \\
\hline$\hat{\beta}_{0}$ & $\tilde{R}_{m, t}^{e}$ & $\begin{array}{l}-0.576 \\
(-12.5)\end{array}$ & $\begin{array}{r}-0.032 \\
(-0.5)\end{array}$ & $\begin{array}{r}-0.032 \\
(-0.6)\end{array}$ & $\begin{array}{r}-0.034 \\
(-0.6)\end{array}$ \\
\hline$\hat{\beta}_{B}$ & $\mathrm{I}_{B, t-1} \cdot \tilde{R}_{m, t}^{e}$ & & $\begin{array}{l}-1.131 \\
(-13.4)\end{array}$ & $\begin{array}{r}-0.661 \\
(-5.0)\end{array}$ & $\begin{array}{r}-0.708 \\
(-6.1)\end{array}$ \\
\hline$\hat{\beta}_{B, U}$ & $\mathrm{I}_{B, t-1} \cdot \mathrm{I}_{U, t} \cdot \tilde{R}_{m, t}^{e}$ & & & $\begin{array}{r}-0.815 \\
(-4.5)\end{array}$ & $\begin{array}{r}-0.727 \\
(-5.6)\end{array}$ \\
\hline$R_{a d j}^{2}$ & & 0.130 & 0.269 & 0.283 & 0.283 \\
\hline
\end{tabular}

\subsection{Option-like Behavior of the WML portfolio}

The source of the bias in estimating ex-post betas of the momentum portfolio is that in down markets the market beta of the WML portfolio is strongly negatively correlated with the contemporaneous realized performance of the portfolio. This means that the ex-post hedge will have a higher market beta when future market returns are high, and a lower beta when future market returns are low, making its performance appear much better.

We also show that the return of the momentum portfolio, net of market risk, is significantly lower in bear markets. Both of these results are linked to the fact that, in bear markets, the momentum strategy behaves as if it is effectively short a call option on the market.

We first illustrate these issues with a set of monthly time-series regressions, the results of which are presented in Table 3 . The variables used in the regressions are:

in a similar way. 
1. $\tilde{R}_{\mathrm{WML}, t}$ is the WML return in month $t$.

2. $\tilde{R}_{m, t}^{e}$ is the CRSP value-weighted (VW) index excess return in month $t$.

3. $\mathrm{I}_{B, t-1}$ is an ex-ante bear-market indicator that equals 1 if the cumulative CRSP VW index return in the past 24 months is negative, and is zero otherwise.

4. $\tilde{\mathrm{I}}_{U, t}$ is the contemporaneous - i.e., not ex-ante - up-market indicator variable. It is 1 if the excess CRSP VW index return is greater than the risk-free rate in month $t$ (e.g., $\left.R_{m, t}^{e}>0\right)$, and is zero otherwise. ${ }^{4}$

Regression (1) in Table 3 fits an unconditional market model to the WML portfolio:

$$
\tilde{R}_{\mathrm{WML}, t}=\alpha_{0}+\beta_{0} \tilde{R}_{m, t}+\tilde{\epsilon}_{t}
$$

Consistent with the results in the literature, the estimated market beta is negative, -0.576 , and the intercept, $\hat{\alpha}$, is both economically large ( $1.85 \%$ per month), and statistically significant $(t$-stat $=7.3)$.

Regression (2) in Table 3 fits a conditional CAPM with the bear market indicator, $I_{B}$, as an instrument:

$$
\tilde{R}_{\mathrm{WML}, t}=\left(\alpha_{0}+\alpha_{B} I_{B, t-1}\right)+\left(\beta_{0}+\beta_{B} I_{B, t-1}\right) \tilde{R}_{m, t}+\tilde{\epsilon}_{t} .
$$

This specification is an attempt to capture both expected return and market-beta differences in bear markets. First, consistent with Grundy and Martin (2001), we see a striking change in the market beta of the WML portfolio in bear markets: it is -1.13 lower, with a $t$-statistic of -13.4 on the difference. The intercept is also lower: the point estimate for the alpha in bear markets - equal to $\hat{\alpha}_{0}+\hat{\alpha}_{B}$ - is now -6.4 basis points per month.

Regression (3) introduces an additional element to the regression which allows us to assess the extent to which the up- and down-market betas of the WML portfolio differ. The specification is similar to that used by Henriksson and Merton (1981) to assess market timing ability of fund managers:

$$
\tilde{R}_{\mathrm{WML}, t}=\left[\alpha_{0}+\alpha_{B} \cdot I_{B, t-1}\right]+\left[\beta_{0}+I_{B, t-1}\left(\beta_{B}+\tilde{I}_{U, t} \beta_{B, U}\right)\right] \tilde{R}_{m, t}+\tilde{\epsilon}_{t} .
$$

If $\beta_{B, U}$ is different from zero, this suggests that the WML portfolio exhibits option-like behavior relative to the market. Specifically, a negative $\beta_{B, U}$ would mean that, in bear markets,

\footnotetext{
${ }^{4}$ Of the 1,035 months in the 1927:01-2013:03 period, there are 183 bear market months by our definition. Also, there are 618 up-months, and 417 down-months.
} 
the momentum portfolio is effectively short a call option on the market. In months when the contemporaneous market return is negative, the point estimate of the WML portfolio beta is $-0.70\left(\hat{\beta}_{0}+\hat{\beta}_{B}\right)$. But, when the market return is positive, the market beta of WML is considerably more negative - specifically, the point estimate is $\hat{\beta}_{0}+\hat{\beta}_{B}+\hat{\beta}_{B, U}=-1.796$.

The predominant source of this optionality comes from the loser portfolio. Panel A of Table 4 presents the results of the regression specification in equation (3) for each of the ten momentum

portfolios. The final row of the table (the $\hat{\beta}_{B, U}$ coefficient) shows the strong up-market betas for the loser portfolios in bear markets. For the loser decile, the down-market beta is 1.560 $(=1.338+0.222)$ and the point estimate of the up-market beta is $2.160(=1.560+0.600)$. Also, note the slightly negative up-market beta increment for the winner decile $(=-0.215)$. This pattern also holds for less extreme winners and losers, such as decile 2 versus decile 9 or decile 3 versus 8, with the differences between winners and losers declining monotonically for less extreme past return sorted portfolios. The net effect is that a momentum portfolio which is long winners and short losers will have significant negative market exposure following bear markets precisely when the market swings upward, and that exposure is even more negative for more extreme past return sorted portfolios.

\subsection{Asymmetry in the Optionality}

The optionality associated with the loser portfolios is only present in bear markets, however. Panel B of Table 4 presents the same set of regressions using the bull-market indicator $I_{L, t-1}$ instead of the bear-market indicator $I_{B, t-1}$. The key variables here are the estimated coefficients and $t$-statistics on $\beta_{L, U}$, presented in the last two rows of Panel B. Unlike in Panel A, there is no significant asymmetry present in the loser portfolio, though the winner portfolio asymmetry is comparable to Panel A. The net effect is that the WML portfolio shows no statistically significant optionality in bull markets, unlike what we see in bear markets.

\subsection{Ex-Ante versus Ex-Post Hedge of Market Risk for WML}

The results of the preceding analysis suggest that calculating hedge ratios based on future realized betas, as in Grundy and Martin (2001), is likely to produce strongly upward biased estimates of the performance of the hedged portfolio. This is because the realized market beta 


\section{Table 4: Momentum Portfolio Optionality}

This table presents the results of regressions of the excess returns of the momentum decile portfolios and the Winner-minus-Loser (WML) long-short portfolio on the CRSP value-weighted excess market returns, and a number of indicator variables. Panel A reports results for optionality in bear markets where for each of the momentum portfolios, the following regression is estimated:

$$
\tilde{R}_{i, t}^{e}=\left[\alpha_{0}+\alpha_{B} I_{B, t-1}\right]+\left[\beta_{0}+I_{B, t-1}\left(\beta_{B}+\tilde{I}_{U, t} \beta_{B, U}\right)\right] \tilde{R}_{m, t}^{e}+\tilde{\epsilon}_{t}
$$

where $R_{m}^{e}$ is the CRSP value-weighted excess market return, $I_{B, t-1}$ is an ex-ante bear-market indicator that equals 1 if the cumulative CRSP VW index return in the past 24 months is negative, and is zero otherwise, and $I_{U, t}$ is a contemporaneous up-market indicator that equals 1 if the excess CRSP VW index return is positive in month $t$, and is zero otherwise. Panel B reports results for optionality in bull markets where for each of the momentum portfolios, the following regression is estimated:

$$
\tilde{R}_{i, t}^{e}=\left[\alpha_{0}+\alpha_{L} I_{L, t-1}\right]+\left[\beta_{0}+I_{L, t-1}\left(\beta_{L}+\tilde{I}_{U, t} \beta_{L, U}\right)\right] \tilde{R}_{m, t}+\tilde{\epsilon}_{t}
$$

where $I_{L, t-1}$ is an ex-ante bull-market indicator (defined as 1- $I_{B, t-1}$ ). The sample period is 1927:01-2013:03.

\begin{tabular}{|c|c|c|c|c|c|c|c|c|c|c|c|}
\hline & \multicolumn{11}{|c|}{$\begin{array}{l}\text { Momentum Decile Portfolios - Monthly Excess Returns } \\
\text { (t-statistics in parentheses) }\end{array}$} \\
\hline & 1 & 2 & 3 & 4 & 5 & 6 & 7 & 8 & 9 & 10 & WML \\
\hline \multicolumn{12}{|c|}{ Panel A: Optionality in Bear Markets } \\
\hline$\hat{\alpha}_{0}$ & $\begin{array}{c}-1.406 \\
(-7.3)\end{array}$ & $\begin{array}{c}-0.804 \\
(-5.7)\end{array}$ & $\begin{array}{c}-0.509 \\
(-4.9)\end{array}$ & $\begin{array}{c}-0.200 \\
(-2.4)\end{array}$ & $\begin{array}{c}-0.054 \\
(-0.7)\end{array}$ & $\begin{array}{c}-0.050 \\
(-0.9)\end{array}$ & $\begin{array}{l}0.159 \\
(2.7)\end{array}$ & $\begin{array}{c}0.260 \\
(4.1)\end{array}$ & $\begin{array}{c}0.294 \\
(3.8)\end{array}$ & $\begin{array}{c}0.570 \\
(4.6)\end{array}$ & $\begin{array}{c}1.976 \\
(7.8)\end{array}$ \\
\hline$\hat{\alpha}_{B}$ & $\begin{array}{l}-0.261 \\
(-0.4)\end{array}$ & $\begin{array}{c}0.370 \\
(0.8)\end{array}$ & $\begin{array}{r}-0.192 \\
(-0.6)\end{array}$ & $\begin{array}{r}-0.583 \\
(-2.1)\end{array}$ & $\begin{array}{r}-0.317 \\
(-1.3)\end{array}$ & $\begin{array}{l}-0.231 \\
(-1.2)\end{array}$ & $\begin{array}{c}-0.001 \\
(-0.0)\end{array}$ & $\begin{array}{r}-0.039 \\
(-0.2)\end{array}$ & $\begin{array}{l}0.420 \\
(1.7)\end{array}$ & $\begin{array}{r}0.321 \\
(0.8)\end{array}$ & $\begin{array}{c}0.583 \\
(0.7)\end{array}$ \\
\hline$\hat{\beta}_{0}$ & $\begin{array}{l}1.338 \\
(30.4)\end{array}$ & $\begin{array}{l}1.152 \\
(35.7)\end{array}$ & $\begin{array}{l}1.014 \\
(42.6)\end{array}$ & $\begin{array}{l}0.955 \\
(49.5)\end{array}$ & $\begin{array}{r}0.922 \\
(55.6)\end{array}$ & $\begin{array}{l}0.952 \\
(72.1)\end{array}$ & $\begin{array}{l}0.974 \\
(72.3)\end{array}$ & $\begin{array}{l}1.018 \\
(69.9)\end{array}$ & $\begin{array}{l}1.114 \\
(62.7)\end{array}$ & $\begin{array}{l}1.306 \\
(46.1)\end{array}$ & $\begin{array}{c}-0.032 \\
(-0.6)\end{array}$ \\
\hline$\hat{\beta}_{B}$ & $\begin{array}{l}0.222 \\
(2.2)\end{array}$ & $\begin{array}{l}0.326 \\
(4.4)\end{array}$ & $\begin{array}{c}0.354 \\
(6.5)\end{array}$ & $\begin{array}{l}0.156 \\
(3.5)\end{array}$ & $\begin{array}{l}0.180 \\
(4.7)\end{array}$ & $\begin{array}{c}0.081 \\
(2.7)\end{array}$ & $\begin{array}{l}0.028 \\
(0.9)\end{array}$ & $\begin{array}{c}-0.126 \\
(-3.8)\end{array}$ & $\begin{array}{r}-0.158 \\
(-3.9)\end{array}$ & $\begin{array}{c}-0.439 \\
(-6.8)\end{array}$ & $\begin{array}{c}-0.661 \\
(-5.0)\end{array}$ \\
\hline$\hat{\beta}_{B, U}$ & $\begin{array}{c}0.600 \\
(4.4)\end{array}$ & $\begin{array}{c}0.349 \\
(3.5)\end{array}$ & $\begin{array}{c}0.180 \\
(2.4)\end{array}$ & $\begin{array}{c}0.351 \\
(5.9)\end{array}$ & $\begin{array}{c}0.163 \\
(3.2)\end{array}$ & $\begin{array}{c}0.121 \\
(3.0)\end{array}$ & $\begin{array}{c}-0.013 \\
(-0.3)\end{array}$ & $\begin{array}{c}-0.031 \\
(-0.7)\end{array}$ & $\begin{array}{c}-0.183 \\
(-3.3)\end{array}$ & $\begin{array}{c}-0.215 \\
(-2.5)\end{array}$ & $\begin{array}{c}-0.815 \\
(-4.5)\end{array}$ \\
\hline \multicolumn{12}{|c|}{ Panel B: Optionality in Bull Markets } \\
\hline$\hat{\alpha}_{0}$ & $\begin{array}{c}0.041 \\
(0.1)\end{array}$ & $\begin{array}{c}0.392 \\
(1.4)\end{array}$ & $\begin{array}{c}-0.249 \\
(-1.2)\end{array}$ & $\begin{array}{c}0.222 \\
(1.3)\end{array}$ & $\begin{array}{c}0.089 \\
(0.6)\end{array}$ & $\begin{array}{c}0.048 \\
(0.4)\end{array}$ & $\begin{array}{c}0.097 \\
(0.8)\end{array}$ & $\begin{array}{c}0.079 \\
(0.6)\end{array}$ & $\begin{array}{c}0.188 \\
(1.2)\end{array}$ & $\begin{array}{c}0.388 \\
(1.5)\end{array}$ & $\begin{array}{c}0.347 \\
(0.7)\end{array}$ \\
\hline$\hat{\alpha}_{L}$ & $\begin{array}{c}-1.436 \\
(-2.9)\end{array}$ & $\begin{array}{c}-1.135 \\
(-3.1)\end{array}$ & $\begin{array}{c}-0.286 \\
(-1.1)\end{array}$ & $\begin{array}{c}-0.653 \\
(-2.9)\end{array}$ & $\begin{array}{c}-0.303 \\
(-1.6)\end{array}$ & $\begin{array}{c}-0.084 \\
(-0.6)\end{array}$ & $\begin{array}{c}-0.164 \\
(-1.1)\end{array}$ & $\begin{array}{c}0.164 \\
(1.0)\end{array}$ & $\begin{array}{c}0.239 \\
(1.2)\end{array}$ & $\begin{array}{c}0.593 \\
(1.9)\end{array}$ & $\begin{array}{c}2.029 \\
(3.1)\end{array}$ \\
\hline$\hat{\beta}_{0}$ & $\begin{array}{l}1.890 \\
(41.3)\end{array}$ & $\begin{array}{l}1.664 \\
(49.6)\end{array}$ & $\begin{array}{l}1.459 \\
(59.2)\end{array}$ & $\begin{array}{l}1.304 \\
(64.5)\end{array}$ & $\begin{array}{l}1.188 \\
(69.3)\end{array}$ & $\begin{array}{l}1.097 \\
(80.5)\end{array}$ & $\begin{array}{l}0.992 \\
(72.2)\end{array}$ & $\begin{array}{l}0.877 \\
(58.7)\end{array}$ & $\begin{array}{l}0.860 \\
(46.7)\end{array}$ & $\begin{array}{l}0.754 \\
(25.9)\end{array}$ & $\begin{array}{l}-1.136 \\
(-18.7)\end{array}$ \\
\hline$\hat{\beta}_{L}$ & $\begin{array}{c}-0.545 \\
(-6.0)\end{array}$ & $\begin{array}{c}-0.498 \\
(-7.4)\end{array}$ & $\begin{array}{c}-0.451 \\
(-9.2)\end{array}$ & $\begin{array}{l}-0.411 \\
(-10.2)\end{array}$ & $\begin{array}{c}-0.308 \\
(-9.0)\end{array}$ & $\begin{array}{c}-0.141 \\
(-5.2)\end{array}$ & $\begin{array}{c}-0.078 \\
(-2.9)\end{array}$ & $\begin{array}{l}0.133 \\
(4.5)\end{array}$ & $\begin{array}{c}0.285 \\
(7.8)\end{array}$ & $\begin{array}{c}0.670 \\
(11.5)\end{array}$ & $\begin{array}{l}1.215 \\
(10.0)\end{array}$ \\
\hline$\hat{\beta}_{L, U}$ & $\begin{array}{c}-0.010 \\
(-0.1)\end{array}$ & $\begin{array}{c}-0.025 \\
(-0.2)\end{array}$ & $\begin{array}{c}0.017 \\
(0.2)\end{array}$ & $\begin{array}{c}0.138 \\
(2.2)\end{array}$ & $\begin{array}{c}0.094 \\
(1.8)\end{array}$ & $\begin{array}{c}-0.006 \\
(-0.1)\end{array}$ & $\begin{array}{l}0.136 \\
(3.2)\end{array}$ & $\begin{array}{c}0.021 \\
(0.4)\end{array}$ & $\begin{array}{r}-0.077 \\
(-1.4)\end{array}$ & $\begin{array}{c}-0.251 \\
(-2.8)\end{array}$ & $\begin{array}{c}-0.242 \\
(-1.3)\end{array}$ \\
\hline
\end{tabular}
The coefficients $\hat{\alpha}_{0}, \hat{\alpha}_{B}$ and $\hat{\alpha}_{L}$ are $\times 100$ (i.e., are in percent per month). 

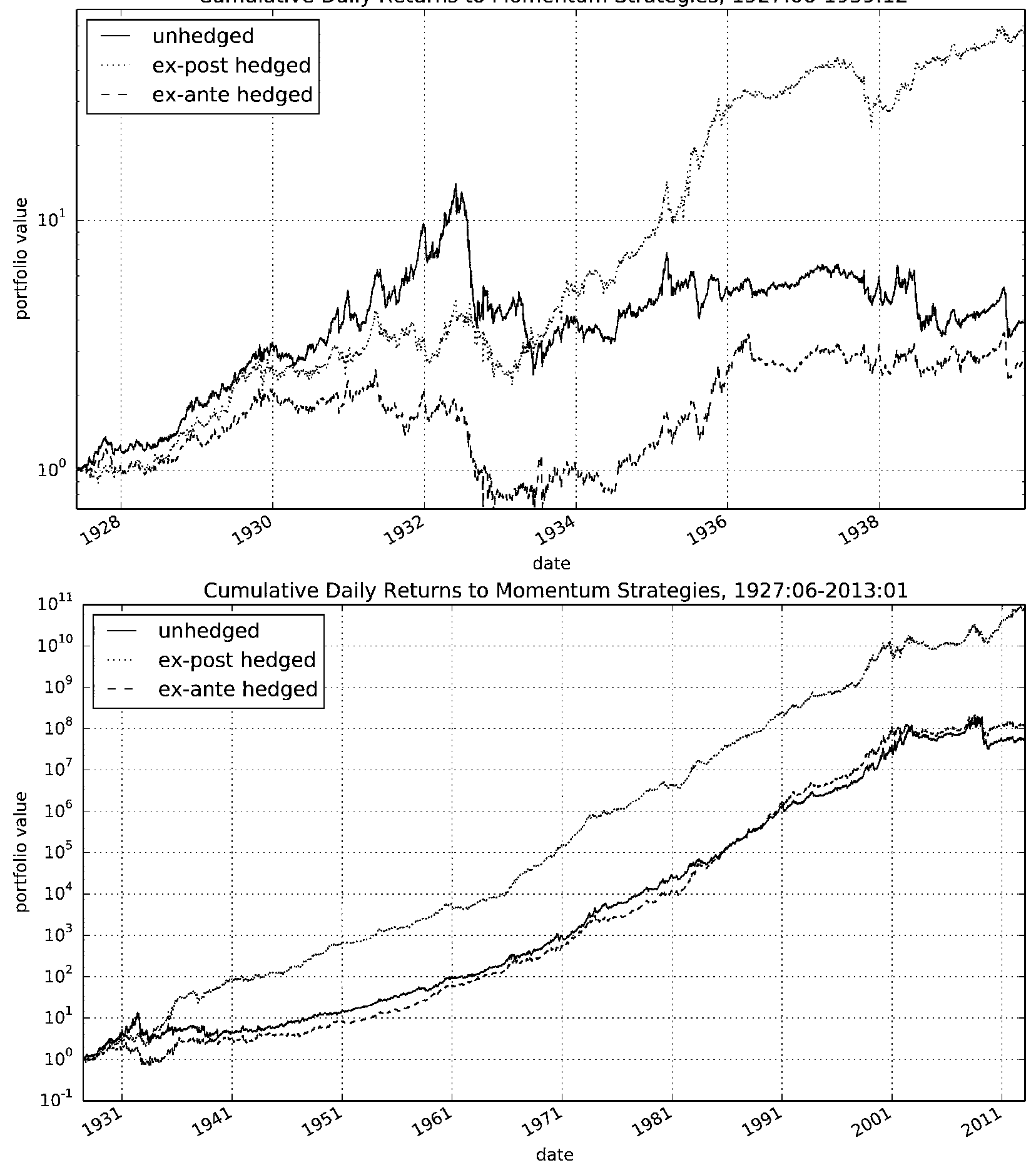

Figure 4: $\boldsymbol{E} \boldsymbol{x}$-Ante vs. Ex-Post Hedged Portfolio Performance

Plotted are the cumulative returns to the baseline static WML strategy, the WML strategy hedged ex-post with respect to the market, and the WML strategy hedged ex-ante with respect to the market. The ex post hedged portfolio conditionally hedges the market exposure using the ex-post hedged procedure of Grundy and Martin (2001), but using daily data. Specifically, the size of the market hedge is based on the future 42-day (2 month) realized market beta of the WML portfolio using equation (2). The ex-ante hedged momentum portfolio estimates market betas using the lagged 42 days of returns on the portfolio and the market from equation (2). The first graph plots the cumulative log returns of the three portfolios over the 1927:06 to 1939:12 period and the second graph plots their cumulative returns over the full sample period from 1927:06 to 2013:03. 
of the momentum portfolio is more negative when the realized return of the market is positive. Thus, hedging ex-post - where the hedge is based on the future realized portfolio beta - buys the market (as a hedge) when the future market return is high, leading to a strong upward bias in the estimated performance of the hedged portfolio.

To see how big the bias is, Figure 4 plots the cumulative log return to the static unhedged, ex-post hedged, and an ex-ante hedged WML momentum portfolio. ${ }^{5}$ The ex-post hedged portfolio takes the WML portfolio and hedges out market risk using an ex-post estimate of market beta. Following Grundy and Martin (2001), we construct the ex-post hedged portfolio based on WML's future 42-day (2 month) realized market beta, estimated using daily data. Again, to calculate the beta we use 10 daily lags of the market return. The ex-ante hedged portfolio estimates market betas using the lagged 42 days of returns of the portfolio on the market, including 10 daily lags.

The first graph in Figure 4 plots the cumulative log returns to all three momentum portfolios over the June 1927 to December 1939 period, covering a few years before, during, and after the biggest momentum crash. The ex-post hedged portfolio exhibits considerably improved performance over the unhedged momentum portfolio as it is able to avoid the crash. However, the ex-ante hedged portfolio is not only unable to avoid or mitigate the crash, but also underperforms the unhedged portfolio over this period. Hence, trying to hedge ex-ante, as an investor would in reality, would have made an investor worse off. The bias in using ex-post betas is substantial over this period.

The second graph in Figure 4 plots the cumulative log returns of the three momentum portfolios over the full sample period from 1927 to 2013. Again, the strong bias in the ex-post hedge is clear, as the ex ante hedged portfolio performs no better than the unhedged WML portfolio in the overall period and significantly worse than the ex post hedged portfolio.

\subsection{Market Stress and Momentum Returns}

A casual interpretation of the results presented in Section 3.2 is that there are option-like payoffs associated with the past losers in bear markets, and that the value of this option is not adequately reflected in the prices of past losers. This interpretation further suggests that

\footnotetext{
${ }^{5}$ The calculation of cumulative returns for long-short portfolios is described in Appendix A.1.
} 


\section{Table 5: Momentum Returns and Estimated Market Variance}

Each column of this table presents the estimated coefficients and $t$-statistics for a time-series regression based on the following regression specification:

$$
\tilde{R}_{\mathrm{WML}, t}=\gamma_{0}+\gamma_{\mathrm{B}} \cdot \mathrm{I}_{B, t-1}+\gamma_{\sigma_{m}^{2}} \cdot \hat{\sigma}_{m, t-1}^{2}+\gamma_{i n t} \cdot \mathrm{I}_{\mathrm{B}, \mathrm{t}-1} \cdot \hat{\sigma}_{m, t-1}^{2}+\tilde{\epsilon}_{t},
$$

where $\mathrm{I}_{B, t-1}$ is the bear market indicator and $\hat{\sigma}_{m, t-1}^{2}$ is the variance of the daily returns on the market, measured over the 126-days preceding the start of month $t$. The regression is estimated using monthly data over the period 1927:07-2013:03. The coefficients $\hat{\gamma}_{0}$ and $\hat{\gamma}_{B}$ are $\times 100$ (i.e., are in percent per month).

\begin{tabular}{lccccc}
\hline & $(1)$ & $(2)$ & $(3)$ & $(4)$ & $(5)$ \\
\cline { 2 - 6 }$\hat{\gamma}_{0}$ & 1.955 & 2.428 & 2.500 & 1.973 & 2.129 \\
& $(6.6)$ & $(7.5)$ & $(7.7)$ & $(7.1)$ & $(5.8)$ \\
$\hat{\gamma}_{B}$ & -2.626 & & -1.281 & & 0.023 \\
& $(-3.8)$ & & $(-1.6)$ & & $(0.0)$ \\
$\hat{\gamma}_{\sigma_{m}^{2}}$ & & -0.330 & -0.275 & & -0.088 \\
& & $(-5.1)$ & $(-3.8)$ & & $(-0.8)$ \\
$\hat{\gamma}_{\text {int }}$ & & & & -0.397 & -0.323 \\
& & & & $(-5.7)$ & $(-2.2)$ \\
& & & & & \\
\hline
\end{tabular}

the value of this option should be a function of the future variance of the market.

To examine this hypothesis, we use daily market return data to construct an ex-ante estimate of the market volatility over the next month, and use this market variance estimate in combination with the bear-market indicator, $I_{\mathrm{B}, \mathrm{t}-1}$, to forecast future WML returns. Specifically, we run the following regression:

$$
\tilde{R}_{\mathrm{WML}, t}=\gamma_{0}+\gamma_{\mathrm{B}} \cdot \mathrm{I}_{\mathrm{B}}+\gamma_{\sigma_{m}^{2}} \cdot \hat{\sigma}_{m, t-1}^{2}+\gamma_{i n t} \cdot \mathrm{I}_{\mathrm{B}} \cdot \hat{\sigma}_{m, t-1}^{2}+\tilde{\epsilon}_{t},
$$

where $\mathrm{I}_{\mathrm{B}}$ is the bear market indicator and $\hat{\sigma}_{m, t-1}^{2}$ is the variance of the daily returns of the market over the 126-days prior to time $t$.

Table 5 reports the regression results, showing that both estimated market variance and the bear market indicator independently forecast future momentum returns. Columns (1) and (2) report regression results for each variable separately and column (3) reports results using both variables simultaneously. The results are consistent with those from the previous section: in periods of high market stress, as indicated by bear markets and high volatility, future momentum returns are low. Finally, the last two columns of Table 5 report results for 


\section{Table 6: Regression of WML Returns on Variance Swap Returns}

This table presents the results of three daily time-series regressions of the zero-investment WML portfolio returns on an intercept $\alpha$, on the normalized ex-ante forecasting variable $\mathrm{I}_{B, t-1} \hat{\sigma}_{m}^{2}$, and on this forecasting variable interacted with the excess market return and the return on a (zero-investment) variance swap on the S\&P 500. (See Appendix A.2 for details on how these swap returns are calculated.) The sample is January 2, 1990 to March 28, 2013. T-statistics are in parentheses. The intercept $(\alpha)$ and the coefficient for $\mathrm{I}_{B \sigma^{2}}$ are converted to annualized, percentage terms by multiplying by $252 \times 100$.

\begin{tabular}{lccc}
\hline & $(1)$ & $(2)$ & $(3)$ \\
\hline & & & \\
& 31.48 & 29.93 & 30.29 \\
$\mathrm{I}_{B \sigma^{2}}$ & $(4.7)$ & $(4.8)$ & $(4.9)$ \\
& -58.62 & -49.16 & -54.83 \\
$\tilde{r}_{m, t}^{e}$ & $(-5.2)$ & $(-4.7)$ & $(-5.3)$ \\
& & 0.11 & 0.10 \\
$\mathrm{I}_{B \sigma^{2}} \cdot \tilde{r}_{m, t}^{e}$ & & $(4.5)$ & $(3.1)$ \\
& & -0.52 & -0.63 \\
$\tilde{r}_{v s, t}$ & & $(-28.4)$ & $(-24.7)$ \\
& & & -0.02 \\
$\mathrm{I}_{B \sigma^{2}} \cdot \tilde{r}_{v s, t}$ & & & $(-0.4)$ \\
& & & -0.10 \\
& & & $(-4.7)$ \\
\hline
\end{tabular}

the interaction between the bear market indicator and volatility, where momentum returns are shown to be particularly poor during bear markets with high volatility.

\subsection{Exposure to other risk factors}

Our results show that time varying exposure to market risk cannot explain the low returns of the momentum portfolio in "crash" states. However, the option-like behavior of the momentum portfolio raises the intriguing question of whether the premium associated with momentum might be related to exposure to variance risk since, in panic states, a long-short momentum portfolio behaves like a short (written) call option on the market and since shorting options (i.e., selling variance) has historically earned a large premium. ${ }^{6}$

To assess the dynamic exposure of the momentum strategy to variance innovations, we regress

\footnotetext{
${ }^{6}$ See Christensen and Prabhala (1998) and Carr and Wu (2009).
} 
daily WML returns on the inferred daily (excess) returns of a variance swap on the S\&P 500, which we calculate using the VIX and S\&P 500 returns. Appendix A.2 provides details of the return calculations. We run a time-series regression with a conditioning variable designed to capture the time-variation in factor loadings on the market, and potentially on other variables. The conditioning variable $\mathrm{I}_{\mathrm{B} \sigma^{2}} \equiv\left(1 / \bar{v}_{B}\right) \mathrm{I}_{B, t-1} \hat{\sigma}_{m, t-1}^{2}$ is the interaction used earlier but with a slight twist:

- $\mathrm{I}_{\mathrm{B}}$ is the bear market indicator defined earlier $\left(\mathrm{I}_{\mathrm{B}}=1\right.$ if the cumulative past two-year market return is negative, and is zero otherwise).

- $\hat{\sigma}_{m}^{2}$ is the variance of the market excess return over the preceding 126 days.

- $\left(1 / \bar{v}_{B}\right)$ is the inverse of the full-sample mean of $\hat{\sigma}_{m}^{2}$ over all months in which $\mathrm{I}_{B, t-1}=1$.

Normalizing the interaction term with the constant $1 / \bar{v}_{B}$ does not affect the statistical significance of the results, but it gives the coefficients a simple interpretation. Specifically, since

$$
\sum_{\mathrm{I}_{B, t-1}=1} \mathrm{I}_{B \sigma^{2}}=1
$$

the coefficients on $\mathrm{I}_{B \sigma^{2}}$ and on variables interacted with $\mathrm{I}_{B \sigma^{2}}$ can be interpreted as the weighted average change in the corresponding coefficient during a bear market, where the weight on each observation is proportional to the ex-ante market variance leading up to that month.

Table 6 presents the results of this analysis. In regression (1) the intercept $(\alpha)$ estimates the mean return of the WML portfolio when $\mathrm{I}_{B, t-1}=0$ as $31.48 \%$ per year. However, the coefficient on $\mathrm{I}_{B \sigma^{2}}$ shows that the weighted-average return in "panic" periods (volatile bear markets) is almost $59 \%$ per year lower.

Regression (2) controls for the market return and conditional market risk. Consistent with our earlier results, the last coefficient in this column shows that the estimated WML beta falls by 0.518 ( $t$-stat $=-28.4)$ in panic states. However, both the mean WML return in good periods and the change in the WML premium in the panic periods (given, respectively, by $\alpha$ and the coefficient on $\mathrm{I}_{B \sigma^{2}}$ ), remain about the same.

In regression (3), we add the return on the variance swap and its interaction with panic states. The coefficient on $\tilde{r}_{v s, t}$ shows that outside of panic states (i.e., when $\mathrm{I}_{B, t-1}=0$ ), the 
WML return does not covary significantly with the variance swap. However, the coefficient on $\mathrm{I}_{B \sigma^{2}} \cdot \tilde{r}_{v s, t}$ shows that in panic states, WML has a strongly significant negative loading on the variance swap return. That is, WML is effectively "short volatility" during these periods. This is consistent with our previous results, where WML behaves like a short call option, but only in panic periods; outside of these periods, there is no evidence of any optionality.

However, the intercept and estimated $\mathrm{I}_{B \sigma^{2}}$ coefficient in regression (3) are essentially unchanged, even after controlling for the variance swap return. The estimated WML premium in non-panic states remains large, and the change in this premium in panic states is just as negative as before, indicating that although momentum returns are related to variance risk, neither the unconditional nor conditional returns to momentum are explained by it.

We also regress the WML momentum portfolio returns on the three Fama and French (1993) factors consisting of the CRSP VW index return in excess of the risk-free rate, a small minus big (SMB) stock factor, and a high BE/ME minus low BE/ME (HML) factor, all obtained from Ken French's website. In addition, we interact each of the factors with the panic state variable $I_{B \sigma^{2}}$. The results are reported in Appendix B, where the abnormal performance of momentum continues to be significantly more negative in bear market states, whether we measure abnormal performance relative to the market model or to the Fama and French (1993) three-factor model, with little difference in the point estimates. ${ }^{7}$

\section{Dynamic Weighting of the Momentum Portfolio}

Using the insights from the previous section, we evaluate the performance of a strategy which dynamically adjusts the weight on the WML momentum strategy using the forecasted return and variance of the strategy. We show that the dynamic strategy generates a Sharpe ratio more than double that of the baseline \$1-long/\$1-short WML strategy and is not explained by other factors or other suggested dynamic momentum portfolios such as constant volatility (e.g., Barroso and Santa-Clara (2012)).

\footnotetext{
${ }^{7}$ Although beyond the scope of this paper, we also examine HML and SMB as the dependent variable in similar regressions. We find that HML has opposite signed market exposure in panic states relative to WML, which isn't surprising since value strategies buy long-term losers and sell winners, the opposite of what a momentum strategy does. The correlation between WML and HML is -0.50 . However, an equal combination of HML and WML does not completely hedge the panic-state optionality as the effects on WML are quantitatively stronger. The details are provided in Appendix B.
} 
We begin with the design of a strategy which dynamically weights WML based on its forecasted return and volatility. We show in Appendix $\mathrm{C}$ that, for the objective function of maximizing the in-sample unconditional Sharpe ratio, the optimal weight on the risky asset (WML) at time $t-1$ is:

$$
w_{t-1}^{*}=\left(\frac{1}{2 \lambda}\right) \frac{\mu_{t-1}}{\sigma_{t-1}^{2}}
$$

where $\mu_{t-1} \equiv \mathbb{E}_{t-1}\left[R_{\mathrm{WML}, t}\right]$ is the conditional expected return on the (zero-investment) WML portfolio over the coming month, $\sigma_{t-1}^{2} \equiv \mathbb{E}_{t-1}\left[\left(R_{\mathrm{WML}, t}^{2}-\mu_{t-1}\right)^{2}\right]$ is the conditional variance of the WML portfolio return over the coming month, and $\lambda$ is a time-invariant scalar that controls the unconditional risk and return of the dynamic portfolio.

We use the insights from our previous analysis to provide an estimate of $\mu_{t-1}$, the conditional mean return of WML. The results from Table 5 provide us with an instrument for the time $t$ conditional expected return on the WML portfolio. As a proxy for the expected return, we use the fitted regression of the WML returns on the interaction between the bear-market indicator $I_{B, t-1}$ and the market variance over the preceding 6 -months - i.e., the regression estimated in the last column of Table 5.

To forecast the volatility of the WML series, we first fit a GARCH model as proposed by Glosten, Jagannathan, and Runkle (1993, GJR) to the WML return series. The process is defined by:

$$
R_{W M L, t}=\mu+\epsilon_{t},
$$

where $\epsilon_{t} \sim \mathcal{N}\left(0, \sigma_{t}^{2}\right)$ and where the evolution of $\sigma_{t}^{2}$ is governed by the process:

$$
\sigma_{t}^{2}=\omega+\beta \sigma_{t-1}^{2}+\left(\alpha+\gamma I\left(\epsilon_{t-1}<0\right)\right) \epsilon_{t-1}^{2}
$$

where $I\left(\epsilon_{t-1}<0\right)$ is an indicator variable equal to one if $\epsilon_{t-1}<0$, and zero otherwise. ${ }^{8}$ We use maximum likelihood to estimate the parameter set $(\mu, \omega, \alpha, \gamma, \beta)$ over the full time series (estimates of the parameters and standard errors are provided in Appendix D).

We form a linear combination of the forecast of future volatility from the fitted GJR-GARCH process with the realized standard deviation of the 126 daily returns preceding the current month. We show in Appendix D that both components contribute to forecasting future daily

\footnotetext{
${ }^{8}$ Engle and $\mathrm{Ng}$ (1993) investigate the performance of a number of parametric models in explaining daily market volatility for Japan. They find that the GJR model that we use here best fits the dynamic structure of volatility for that market.
} 
realized WML volatility.

Our analysis in this section is also related to work by Barroso and Santa-Clara (2012), who argue that momentum crashes can be avoided with a momentum portfolio that is scaled by its trailing volatility. They further show that the unconditional Sharpe ratio of the constantvolatility momentum strategy is far better than a simple $\$ 1$-long $/ \$ 1$-short strategy.

Equation (5) shows that our results would be approximately the same as those of Barroso and Santa-Clara (2012) if the Sharpe ratio of the momentum strategy were time-invariant, i.e., if the forecast mean were always proportional to the forecast volatility. Equation (5) shows that, in this setting, the weight on WML would be inversely proportional to the forecast WML volatility - that is the optimal dynamic strategy would be a constant volatility strategy like the one proposed by Barroso and Santa-Clara (2012).

However, this is not the case for momentum. In fact, the return of WML is actually negatively related to the forecast WML return volatility, related in part to our findings of lower momentum returns following periods of market stress. This means that the Sharpe ratio of the optimal dynamic portfolio varies over time, and indeed is lowest when WML's volatility is forecast to be high (and it's mean return low). To test this hypothesis, we implement a dynamic momentum portfolio using these insights in the next subsection, and show that the dynamic strategy outperforms a constant volatility strategy.

\subsection{Dynamic Strategy Performance}

Figure 5 plots the cumulative returns to the dynamic strategy from July 1927 to March 2013, where $\lambda$ is chosen so that the in-sample annualized volatility of the strategy is $19 \%$ - the same as that of the CRSP value-weighted index over the full sample. For comparison, we also plot the cumulative log returns of the static WML strategy, and a constant volatility strategy similar to that of Barroso and Santa-Clara (2012) also scaled to $19 \%$ annual volatility. As Figure 5 shows, the dynamic portfolio outperforms the constant volatility portfolio, which in turn outperforms the basic WML portfolio. The Sharpe ratio (in parentheses on the figure) of the dynamic portfolio is nearly twice that of the static WML portfolio and a bit higher than the constant volatility momentum portfolio. In Section 4.3 we will conduct formal spanning tests among these portfolios as well as other factors. Consistent with our previous results, part 

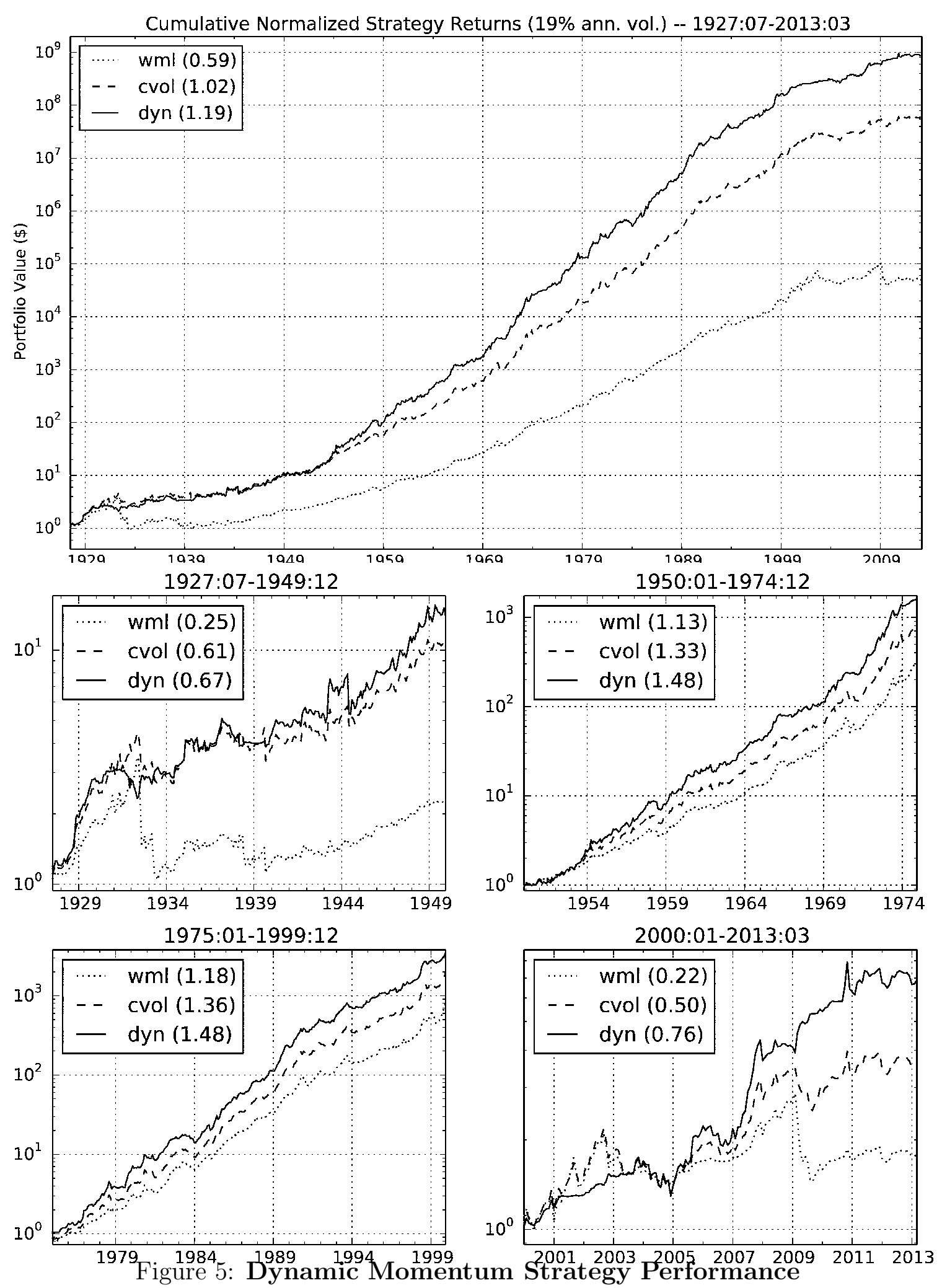

Plotted are the cumulative returns to the dynamic strategy, "dyn", from equation (5), where $\lambda$ is chosen so that the in-sample annualized volatility of the strategy is $19 \%$ - the same as that of the CRSP value-weighted index over the full sample. For comparison, we also plot the cumulative log returns of the static WML strategy, and a constant volatility strategy, "cvol", similar to that of Barroso and Santa-Clara (2012), also targeted for an annualized volatility of $19 \%$. The first graph plots the cumulative returns over the full sample period from 1927:07 to 2013:03. The second graph plots the returns over four roughly quarter-century subsamples: 1927-1949, 1950-1974, 1975-1999, and 2000-2013. Annualized Sharpe ratios of each strategy in each period are reported in parentheses on the graphs. 
of the outperformance of the dynamic strategy comes from its ability to mitigate momentum crashes. However, the dynamic strategy still outperforms the other momentum strategies even outside of the 1930s and the financial crisis period, as we discuss next.

\subsection{Subsample Performance}

As a check on the robustness of our results, we perform the same analysis over a set of approximately quarter-century subsamples: 1927 to 1949, 1950 to 1974, 1975 to 1999, and 2000 to 2013. We use the same mean and variance forecasting equation and the same calibration in each of the four subsamples. Figure 5 plots the cumulative log returns by subsample and presents the strategy Sharpe ratios (in parentheses) by subsample. For these plots, returns for each of the strategies are scaled to an annualized volatility of $19 \%$ in each subsample for ease of comparison.

In each of the subsamples, the ordering of performance remains the same: the dynamic strategy outperforms the constant volatility strategy, which outperforms the static WML strategy. As the subsample plots show, part of the improved performance of the constant volatility, and especially dynamic strategy, over the static WML portfolio is the amelioration of big crashes, but even over sub-periods devoid of those crashes, there is still improvement.

\subsection{Spanning Tests}

A more formal test of the dynamic portfolio's success is to conduct spanning tests with respect to the other momentum strategies and other factors. Using daily returns, we regress the dynamic portfolio's returns on a host of factors that include the market and Fama and French (1993) factors as well as the static WML and constant volatility (cvol) portfolios. The annualized alphas from these regressions are reported in Table 7.

The first column of Panel A of Table 7 reports results from regressions of our dynamic momentum portfolio on the market plus the static momentum portfolio, WML. The intercept is

highly significant at 23.74 percent per annum $(t$-stat $=11.99)$, indicating that the dynamic portfolio's returns are not captured by the market or the static momentum portfolio. Since this regression only controls for unconditional market exposure, the second column of Panel 


\section{Table 7: Spanning Tests of the Dynamic Momentum Portfolio}

This table presents the results of spanning tests of the dynamic (Panel A) and constant volatility (Panel B) portfolios with respect to the market (Mkt), Fama and French (1993) factors (Mkt, SMB, HML), the static WML portfolio, and each other by running daily time-series regressions of the dynamic portfolio's (dyn) and constant volatility (cvol) portfolio's returns on these factors. In addition, we interact each of these factors with the market stress indicator $I_{B \sigma^{2}}$ to estimate conditional betas with respect to these factors, which are labeled "conditional." For ease of comparison the dyn and cvol portfolios are scaled to have the same annualized volatility as the static WML portfolio (23\%). The reported intercepts or $\alpha$ 's from these regressions are converted to annualized, percentage terms by multiplying by $252 \times 100$.

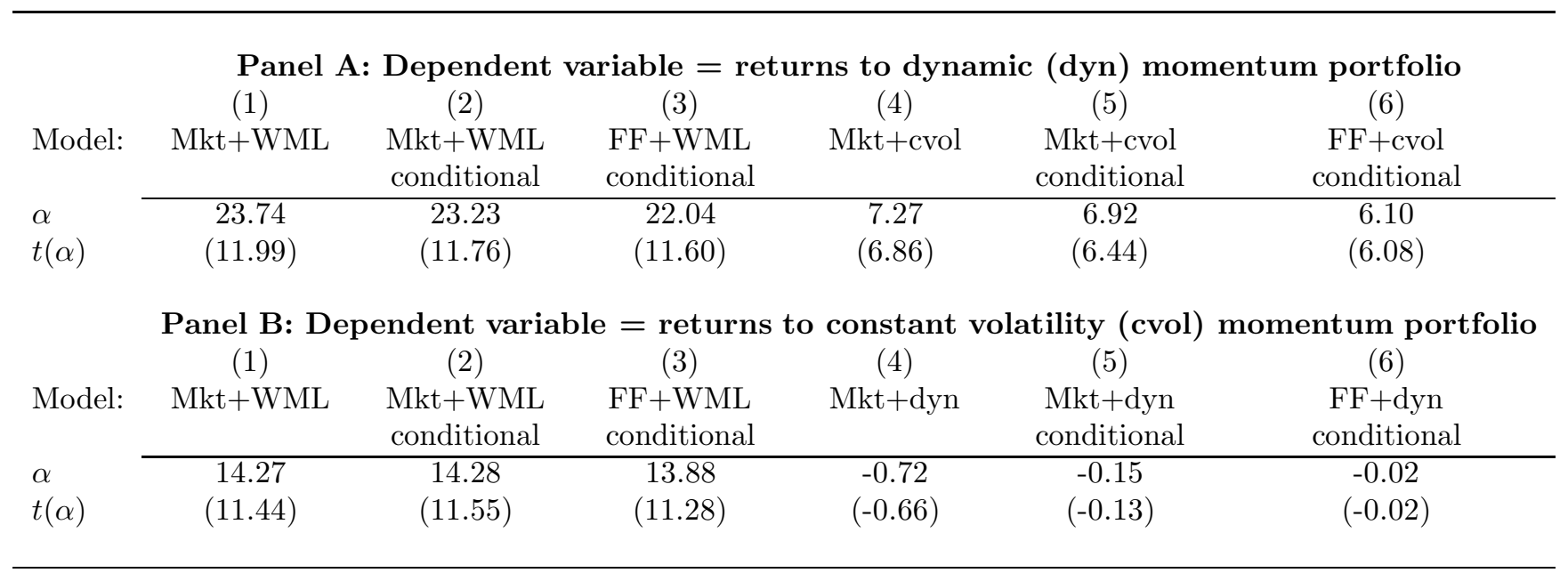

A reports regression results that include interactions of our panic state indicators with the market to capture the conditional variability in beta. The alpha is virtually unchanged and remains highly positively significant. The third column then adds the Fama and French (1993) factors SMB and HML and their interactions with the panic state variables to account for conditional variability in exposure to the market, size, and value factors, where the latter has been shown, for instance, to greatly improve the performance of a momentum portfolio (e.g., Asness, Moskowitz, and Pedersen (2013)). This regression accounts for whether our dynamic portfolio is merely rotating exposure to these factors. ${ }^{9}$ Again, the alpha with respect to this conditional model is strong and significant at 22 percent per year, nearly identical in magnitude to the first two columns. Hence, our dynamic momentum strategy's abnormal performance is not being driven by dynamic exposure to these other factors or to the static momentum portfolio.

Columns (4) through (6) of Panel A of Table 7 repeat the regressions from columns (1) through

\footnotetext{
${ }^{9}$ Since the optimal dynamic portfolio solved in Appendix $\mathrm{C}$ is not conditional on other factors, to form this portfolio in the presence of other factors we first regress the static momentum portfolio on the other factors using daily returns and then use the residuals to form our dynamic strategy by forecasting the conditional mean and variance of those residuals to form the dynamic weights.
} 
(3) by replacing the static WML portfolio with the constant volatility (cvol) momentum portfolio. The alphas drop in magnitude to about 7 percent per year, but remain highly statistically significant ( $t$-stats between 6 and 7 ), suggesting that the dynamic momentum portfolio is not spanned by the constant volatility portfolio.

Panel B of Table 7 flips the analysis around and examines whether the constant volatility portfolio is spanned by the static WML portfolio or the dynamic portfolio. The first three columns of Panel B indicate that the constant volatility portfolio is not spanned by the static WML portfolio or the Fama and French (1993) factors, generating alphas of about 14 percent per annum with highly significant $t$-statistics. These results are consistent with Barroso and Santa-Clara (2012). However, the alphas of the constant volatility portfolio are slightly smaller in magnitude than those from the dynamic strategy, consistent with the Sharpe ratio comparisons from Figure 5. (Since we scale both the dynamic and constant volatility portfolios to have the same variance, these alphas are comparable and give the same rankings as information ratios would.)

Columns (4) through (6) of Panel B report results from regressing the constant volatility portfolio's returns on the dynamic portfolio's returns. Here, the alphas are all zero, both economically and statistically, suggesting that the dynamic portfolio spans the constant volatility portfolio. According to Appendix C, this should be the case in theory, thus implying that we obtain decent ex-ante forecasts of the conditional mean and variance of the static WML portfolio to form a dynamic strategy that reliably captures and improves upon the returns to a constant volatility and static momentum portfolio.

\section{International Equities and Other Asset Classes}

Although first documented in individual equities in the US, subsequent research has demonstrated the existence of strong momentum effects among common stocks in other investment regions and in other asset classes (see Asness, Moskowitz, and Pedersen (2013) for a summary).

We investigate whether the same momentum crash patterns we observe in US equities are also present in these other asset markets, and whether our dynamic momentum portfolio helps ameliorate these crashes and improves momentum performance in other markets. 


\subsection{Data}

The data come from Asness, Moskowitz, and Pedersen (2013) and for equities cover the U.S., U.K., Japan, and Continental Europe. Details on data description and sources can be found in Asness, Moskowitz, and Pedersen (2013). The US and UK data begin in January 1972 and Europe and Japan in February 1974, extending to May 2013. ${ }^{10}$ We also examine a global equity momentum strategy GE, which weights each region's equity momentum strategy by the ex-post volatility of the portfolio over the full sample, following Asness, Moskowitz, and Pedersen (2013).

The non-equity data also come from Asness, Moskowitz, and Pedersen (2013), which contain equity country index futures across 18 developed equity markets beginning in January 1978, 10 currencies across developed markets starting in January 1979, 10 country government bonds beginning January 1982, and 27 different commodity futures beginning in January 1972. All series end in May 2013.

In addition, we examine two composite portfolios: GA is a global momentum strategy across the non-equity asset classes, which weights each asset class momentum strategy portfolio by the ex-post volatility of that portfolio. GAll is a global momentum strategy across all of the equity and non-equity asset classes, which weights the GE and GA portfolios by their ex-post return volatilities over the full sample.

The definition of the market index is different for each market and asset class: it is the MSCI local index for the US, UK, Europe, and Japan, the MSCI World index for country index futures, an equal-weighted average of all country bonds for bond markets, an equal-weighted average of all currencies for currency markets, and the Goldman Sachs Commodity Index (GSCI) for commodities.

\footnotetext{
${ }^{10}$ These data extend beyond the original sample period used in Asness, Moskowitz, and Pedersen (2013), since the data are updated monthly following the same procedure for portfolio construction in Asness, Moskowitz, and Pedersen (2013). The data are available from Toby Moskowitz's website: (http://faculty.chicagobooth.edu/tobias.moskowitz/research/data.html).
} 


\subsection{Cross Sectional Equity Momentum Outside the US}

The portfolio formation procedure here is similar to that used earlier in the paper, except instead of taking the top and bottom decile portfolios, we use the Asness, Moskowitz, and Pedersen (2013) P3-P1 momentum portfolios, which is long the top third and short the bottom third of securities ranked on returns from month $t-12$ to $t-2$. Both the long and the short side of the portfolio are value weighted. As documented in Asness, Moskowitz, and Pedersen (2013), over this time period there are strong momentum effects in each of the regions except Japan.

Panels A through D of Table 8 present the results of the regressions run in Section 2, but here for the other stock market universes. Panel A shows the estimated coefficients and $t$-statistics from the regression specification in equation (2). Consistent with the results presented earlier, the market betas of the momentum strategy are dramatically lower in bear markets across the other stock markets as well. The strategies implemented using European and Japanese stocks have market betas that are approximately 0.5 lower during bear markets (with $t$-stats of about -7). The UK momentum strategy beta falls by 0.2 . The drop in this period for the US momentum strategy is 0.58 - comparable to what we observe for the WML portfolio over the longer 1927 to 2013 period. Globally, averaging across the US, UK, Europe, and Japan, the market betas of the momentum strategy are markedly lower in bear markets.

The abnormal returns of the momentum strategies are significantly positive in bull markets for all regions except Japan. Consistent with our analysis in Section 2, the return is lower in bear markets in each region, though using only the bear market indicator as a proxy for panic periods none of the differences are statistically significant over these shorter sample periods.

Panel B investigates the optionality in the momentum strategy in bear markets using the regression specification in equation (3). Consistent with the longer period US results, there is statistically significant optionality in bear markets in the European, UK, and Japan stock markets, and globally across all markets. Interestingly, for this subsample and methodology, the optionality is of the right sign, but is not statistically significant for the US market. The negative beta of long-short momentum strategies is particularly acute when the contemporaneous market return is positive. That is, momentum strategies in all regions across the world exhibit conditional betas and payoffs similar to writing call options on the local market index. 
In Panel $\mathrm{C}$, we add as a conditioning variable the realized daily market return variance, annualized, over the preceding 126 trading days (6 months): ${ }^{11}$

$$
\tilde{R}_{t}^{P 3-P 1}=\left[\alpha_{0}+\alpha_{B} I_{B, t-1}+\alpha_{V} \hat{\sigma}_{m, t-1}^{2}\right]+\left[\beta_{0}+\beta_{B} I_{B, t-1}+\beta_{V} \hat{\sigma}_{m, t-1}^{2}\right] \tilde{R}_{m, t}^{e}+\tilde{\epsilon}_{t} .
$$

Two interesting results emerge. First, higher ex-ante market variance is generally associated with more negative momentum strategy betas. Second, higher market variance is also associated with strongly lower future abnormal returns to momentum, net of the market return. This last relation is statistically significant in all markets, and again is consistent with our earlier results for the US market over the longer period.

In Panel D we again use the $\mathrm{I}_{B \sigma^{2}} \equiv\left(1 / \bar{v}_{B}\right) \mathrm{I}_{B, t-1} \cdot \hat{\sigma}_{m}^{2}$ measure introduced in Section 3.6, designed to capture "panic" periods when the market has fallen and volatility is high. In addition, in these regressions we instrument for time variation in market beta using $I_{B, t-1}$, $\hat{\sigma}_{m, t-1}^{2}$, and $\mathrm{I}_{B \sigma^{2}}$. Specifically, we run the regression

$$
\tilde{R}_{t}^{P 3-P 1}=\left[\alpha_{0}+\alpha_{B} \mathrm{I}_{\mathrm{B} \sigma^{2}}\right]+\left[\beta_{\mathrm{B}} \mathrm{I}_{\mathrm{B}, \mathrm{t}-1}+\beta_{\mathrm{V}} \hat{\sigma}_{\mathrm{m}, \mathrm{t}-1}^{2}+\beta_{\mathrm{BV}} \mathrm{I}_{\mathrm{B} \sigma^{2}}\right] \tilde{\mathrm{R}}_{\mathrm{m}, \mathrm{t}}^{\mathrm{e}}+\tilde{\epsilon}_{\mathrm{t}} .
$$

The results in Panel D of Table 8 are consistent with our earlier results for the US over the longer period. In particular, the coefficient on the interaction term $I_{B \sigma^{2}}$ is negative, economically large, and statistically significant in all markets, and for the global strategy.

In summary, the results in Table 8 suggest that momentum strategies in these different equity markets are also short volatility, and have significantly lower abnormal returns in panic periods characterized by poor lagged market returns and high market volatility.

One other point of interest is that, in Panels $\mathrm{C}$ and $\mathrm{D}$ of Table 8, the $\hat{\alpha}$ for the Japan momentum strategy is considerably larger, and in Panel C is in fact significant at a 5\% level. We will explore the implications of this finding further in Section 5.4, where we apply a dynamic Japanese momentum strategy which takes into account the forecastability of both the expected return and volatilty.

\footnotetext{
${ }^{11}$ This is the same market variance measure used earlier. However, for the EU, JP, and UK regions we have daily MSCI market return data only for the time period from January $1990 \mathrm{on}$. Therefore, over the period from 1972:01-1990:06 in the UK, and 1974:02-1990:06 in EU and JP, we use the realized monthly variance over the preceding 6 months, again annualized.
} 


\section{Table 8: Time Series Regressions for International Equity Markets}

The table reports the estimated coefficients and $t$-statistics from regressions of the monthly returns to a zeroinvestment equity momentum strategy in each region on the indicated set of independent variables. The estimated regression intercept $(\alpha)$, and the coefficients on $I_{B}$ and $\mathrm{I}_{B \sigma^{2}}$ are all multiplied by $12 \times 100$ to put them in annualized, percentage terms. GE is a global equity momentum strategy that is a volatility-weighted portfolio of the four equity markets.

\begin{tabular}{|c|c|c|c|c|c|}
\hline & $\overline{\mathrm{EU}}$ & JP & UK & US & $\mathrm{GE}$ \\
\hline start & 1974:02 & 1974:02 & 1972:01 & 1972:02 & 1972:01 \\
\hline end & 2013:05 & 2013:05 & 2013:05 & 2013:05 & 2013:05 \\
\hline \multicolumn{6}{|c|}{ Panel A } \\
\hline \multirow[t]{2}{*}{$\alpha$} & 8.935 & 1.887 & 7.409 & 5.181 & 5.826 \\
\hline & $(3.5)$ & $(0.5)$ & $(2.7)$ & $(1.9)$ & $(3.6)$ \\
\hline \multirow[t]{2}{*}{$I_{B}$} & -3.549 & -0.837 & -6.827 & -2.921 & -4.920 \\
\hline & $(-0.7)$ & $(-0.1)$ & $(-1.1)$ & $(-0.5)$ & $(-1.2)$ \\
\hline \multirow{2}{*}{$R_{m}^{e}$} & 0.071 & 0.246 & 0.015 & 0.150 & 0.023 \\
\hline & $(1.6)$ & $(4.8)$ & $(0.4)$ & $(2.7)$ & $(0.7)$ \\
\hline \multirow{2}{*}{$I_{B} R_{m}^{e}$} & -0.508 & -0.527 & -0.197 & -0.584 & -0.275 \\
\hline & $(-7.1)$ & $(-7.0)$ & $(-3.1)$ & $(-6.2)$ & $(-4.6)$ \\
\hline \multicolumn{6}{|c|}{ Panel B } \\
\hline \multirow[t]{2}{*}{$\alpha$} & 8.935 & 1.887 & 7.409 & 5.181 & 5.826 \\
\hline & $(3.6)$ & $(0.5)$ & $(2.7)$ & $(1.9)$ & $(3.6)$ \\
\hline \multirow[t]{2}{*}{$I_{B}$} & 9.418 & 11.104 & 4.249 & -0.266 & 5.019 \\
\hline & $(1.2)$ & $(1.3)$ & $(0.5)$ & $(-0.0)$ & $(0.8)$ \\
\hline \multirow[t]{2}{*}{$R_{m}^{e}$} & 0.071 & 0.246 & 0.015 & 0.150 & 0.023 \\
\hline & $(1.7)$ & $(4.8)$ & $(0.4)$ & $(2.7)$ & $(0.7)$ \\
\hline \multirow[t]{2}{*}{$I_{B} R_{m}^{e}$} & -0.302 & -0.318 & 0.004 & -0.540 & -0.098 \\
\hline & $(-2.7)$ & $(-2.5)$ & $(0.0)$ & $(-3.3)$ & $(-1.0)$ \\
\hline \multirow[t]{2}{*}{$I_{B} I_{U} R_{m}^{e}$} & -0.418 & -0.367 & -0.306 & -0.086 & -0.342 \\
\hline & $(-2.4)$ & $(-2.0)$ & $(-2.2)$ & $(-0.3)$ & $(-2.2)$ \\
\hline \multicolumn{6}{|c|}{ Panel C } \\
\hline \multirow[t]{2}{*}{$\alpha$} & 12.237 & 12.385 & 10.856 & 10.331 & 8.345 \\
\hline & $(4.1)$ & $(2.5)$ & $(3.6)$ & $(3.4)$ & $(4.8)$ \\
\hline \multirow[t]{2}{*}{$I_{B}$} & 1.445 & 4.554 & 0.213 & 6.018 & 2.254 \\
\hline & $(0.3)$ & $(0.7)$ & $(0.0)$ & $(0.9)$ & $(0.5)$ \\
\hline \multirow[t]{2}{*}{$\hat{\sigma}_{m}^{2}$} & -0.113 & -0.221 & -0.078 & -0.204 & -0.252 \\
\hline & $(-2.0)$ & $(-2.9)$ & $(-2.6)$ & $(-3.3)$ & $(-3.7)$ \\
\hline \multirow[t]{2}{*}{$R_{m}^{e}$} & 0.115 & 0.280 & 0.020 & 0.215 & 0.041 \\
\hline & $(2.5)$ & $(4.2)$ & $(0.5)$ & $(3.6)$ & $(1.2)$ \\
\hline \multirow[t]{2}{*}{$I_{B} R_{m}^{e}$} & -0.391 & -0.512 & -0.182 & -0.485 & -0.206 \\
\hline & $(-4.8)$ & $(-6.5)$ & $(-2.5)$ & $(-4.8)$ & $(-3.2)$ \\
\hline \multirow[t]{2}{*}{$\hat{\sigma}_{m}^{2} R_{m}^{e}$} & -1.755 & -0.734 & -0.040 & -2.361 & -1.959 \\
\hline & $(-2.6)$ & $(-0.7)$ & $(-0.2)$ & $(-2.5)$ & $(-2.2)$ \\
\hline \multicolumn{6}{|c|}{ Panel D } \\
\hline \multirow[t]{2}{*}{$\alpha$} & 10.286 & 5.333 & 8.627 & 7.084 & 6.720 \\
\hline & $(4.4)$ & $(1.6)$ & $(3.4)$ & $(2.8)$ & $(4.5)$ \\
\hline \multirow[t]{2}{*}{$I_{B \sigma^{2}}$} & -6.509 & -9.910 & -11.408 & -11.055 & -8.704 \\
\hline & $(-2.0)$ & $(-2.2)$ & $(-3.2)$ & $(-2.6)$ & $(-3.6)$ \\
\hline \multirow[t]{2}{*}{$I_{B} R_{m}^{e}$} & -0.306 & -0.180 & -0.176 & -0.245 & -0.177 \\
\hline & $(-3.7)$ & $(-1.8)$ & $(-2.6)$ & $(-2.4)$ & $(-2.8)$ \\
\hline \multirow[t]{2}{*}{$\hat{\sigma}_{m}^{2} R_{m}^{e}$} & -0.295 & 3.685 & -0.600 & 1.839 & -2.798 \\
\hline & $(-0.2)$ & $(3.8)$ & $(-0.8)$ & $(1.2)$ & $(-1.2)$ \\
\hline$I_{B \sigma^{2}} R_{m}^{e}$ & -0.056 & -0.307 & 0.073 & -0.261 & 0.036 \\
\hline & $(-0.7)$ & $(-3.2)$ & $(0.8)$ & $(-2.4)$ & $(0.5)$ \\
\hline
\end{tabular}




\subsection{Cross-Sectional Momentum in Other Asset Classes}

Evidence of the option-like payoffs of momentum strategies in bear markets outside of US equities, and indeed in every other equity market we examined, gives credence to this feature of momentum being a robust phenomenon and not likely due to chance. For further robustness, we also examine momentum strategies in the non-equity asset classes. In addition to providing another out of sample test for the option-like payoffs of momentum strategies in bear markets, finding the same option-like asymmetry in these asset classes would also present a challenge to the Merton (1974) explanation.

Table 9 presents the results of time series regressions for the non-equity asset-class momentum strategies similar to those in Table 8 for international equities. First, the set of $\mathrm{I}_{B, t-1}$. $\tilde{R}_{m}^{e}$ coefficients and $t$-statistics in the last row of Panel A show that, in all asset classes, the momentum portfolio's market beta is significantly more negative in bear markets. The intuition that, following a bear market, the loser side of the momentum portfolio will have a high market beta is valid for other asset classes as well. The $\mathrm{I}_{B, t-1}$ coefficients in the second row of Panel A also provide evidence weakly consistent with the earlier finding that marketadjusted momentum returns are lower following bear markets. The point estimates are all negative, except for bonds, but only in the currency market is the coefficient significant.

Panel B assesses whether the optionality present in cross-sectional equity momentum strategies is also present in other asset classes. The $\mathrm{I}_{B, t-1} \tilde{\mathrm{I}}_{U, t} \tilde{R}_{m, t}^{e}$ coefficient is negative for each of the four asset classes, and the two composite portfolios, but is statistically significant at a $5 \%$ level only for commodities. This result is intriguing. While a model such as Merton (1974) argues that equities should exhibit option-like features, it is not clear that such a model would easily explain the optionality present in commodity futures, and weakly in currency markets.

Panel C of Table 9 estimates equation (8) for the other-asset-class momentum strategies. Here the signs in the relation between lagged volatility and momentum strategy returns are again negative in the commodity (CM), currency (FX), and equity (EQ) futures asset classes. Panel $\mathrm{D}$ again uses the interactive variable $I_{B \sigma^{2}}$ as an instrument for volatile bear markets. As in Table 8, we control for variation in market beta associated with $I_{B, t-1}, \hat{\sigma}_{m}^{2}$, and the interaction term itself. In all asset classes except FI, the coefficient on this interaction term is negative, consistent with our previous findings in US and international equity markets. However, except for FX and the GAll portfolio, the coefficient is not significant at a $5 \%$ level. 


\section{Table 9: Time Series Regressions for other Asset Classes}

The table reports the estimated coefficients and $t$-statistics from regressions of the monthly returns to zeroinvestment momentum strategies in each asset class on the indicated set of independent variables. $G A$ and GAll are the global strategies across all non-equity asset classes and across all asset classes including equities, where each asset class and equity market is weighted by the inverse of their full sample volatility. The estimated intercept, and the coefficients on $I_{B, t-1}$ and $\mathrm{I}_{B \sigma^{2}}$ are all multiplied by $12 \times 100$ to put them in annualized, percentage terms.

\begin{tabular}{|c|c|c|c|c|c|c|}
\hline \multirow{4}{*}{$\begin{array}{r}\text { start } \\
\text { end }\end{array}$} & FI & CM & FX & EQ & GA & GAll \\
\hline & 1983:02 & 1973:02 & 1980:02 & 1979:02 & $\begin{array}{l}1973: 02 \\
\end{array}$ & $\overline{1973: 02}$ \\
\hline & 2013:05 & 2013:05 & 2013:05 & 2013:05 & 2013:05 & 2013:05 \\
\hline & \multicolumn{6}{|c|}{ Panel A } \\
\hline$\alpha$ & $\begin{array}{c}0.006 \\
(0.0)\end{array}$ & $\begin{array}{c}16.302 \\
(3.7)\end{array}$ & $\begin{array}{l}4.745 \\
(2.2)\end{array}$ & $\begin{array}{c}8.575 \\
(3.8)\end{array}$ & $\begin{array}{l}4.653 \\
(4.6)\end{array}$ & $\begin{array}{l}4.639 \\
(5.0)\end{array}$ \\
\hline$I_{B}$ & $\begin{array}{c}0.798 \\
(0.3)\end{array}$ & $\begin{array}{c}-10.470 \\
(-1.4)\end{array}$ & $\begin{array}{l}-8.221 \\
(-2.5)\end{array}$ & $\begin{array}{c}-0.575 \\
(-0.1)\end{array}$ & $\begin{array}{c}-2.426 \\
(-1.1)\end{array}$ & $\begin{array}{c}-3.294 \\
(-1.3)\end{array}$ \\
\hline$R_{m}^{e}$ & $\begin{array}{c}0.186 \\
(3.1)\end{array}$ & $\begin{array}{l}0.308 \\
(4.1)\end{array}$ & $\begin{array}{l}0.382 \\
(4.4)\end{array}$ & $\begin{array}{c}0.272 \\
(6.0)\end{array}$ & $\begin{array}{c}0.162 \\
(2.7)\end{array}$ & $\begin{array}{c}0.082 \\
(1.9)\end{array}$ \\
\hline$I_{B} R_{m}^{e}$ & $\begin{array}{c}-0.362 \\
(-2.7)\end{array}$ & $\begin{array}{c}-0.730 \\
(-4.5)\end{array}$ & $\begin{array}{c}-1.092 \\
(-8.6)\end{array}$ & $\begin{array}{l}-0.620 \\
(-8.5)\end{array}$ & $\begin{array}{l}-0.485 \\
(-3.9)\end{array}$ & $\begin{array}{c}-0.366 \\
(-4.4)\end{array}$ \\
\hline \multicolumn{7}{|c|}{ Panel B } \\
\hline$\alpha$ & $\begin{array}{c}0.006 \\
(0.0)\end{array}$ & $\begin{array}{c}16.302 \\
(3.8)\end{array}$ & $\begin{array}{l}4.745 \\
(2.2)\end{array}$ & $\begin{array}{l}8.575 \\
(3.8)\end{array}$ & $\begin{array}{l}4.653 \\
(4.6)\end{array}$ & $\begin{array}{l}4.639 \\
(5.1)\end{array}$ \\
\hline$I_{B}$ & $\begin{array}{c}1.994 \\
(0.6)\end{array}$ & $\begin{array}{l}7.014 \\
(0.7)\end{array}$ & $\begin{array}{c}-4.096 \\
(-0.9)\end{array}$ & $\begin{array}{c}6.248 \\
(1.1)\end{array}$ & $\begin{array}{l}1.142 \\
(0.4)\end{array}$ & $\begin{array}{c}3.746 \\
(1.1)\end{array}$ \\
\hline$R_{m}^{e}$ & $\begin{array}{c}0.186 \\
(3.1)\end{array}$ & $\begin{array}{l}0.308 \\
(4.1)\end{array}$ & $\begin{array}{l}0.382 \\
(4.4)\end{array}$ & $\begin{array}{c}0.272 \\
(6.0)\end{array}$ & $\begin{array}{c}0.162 \\
(2.7)\end{array}$ & $\begin{array}{c}0.082 \\
(1.9)\end{array}$ \\
\hline$I_{B} R_{m}^{e}$ & $\begin{array}{c}-0.278 \\
(-1.4)\end{array}$ & $\begin{array}{c}-0.205 \\
(-0.8)\end{array}$ & $\begin{array}{c}-0.911 \\
(-5.0)\end{array}$ & $\begin{array}{c}-0.485 \\
(-4.6)\end{array}$ & $\begin{array}{c}-0.222 \\
(-1.2)\end{array}$ & $\begin{array}{c}-0.106 \\
(-0.9)\end{array}$ \\
\hline$I_{B} I_{U} R_{m}^{e}$ & $\begin{array}{r}-0.197 \\
(-0.6) \\
\end{array}$ & $\begin{array}{c}-1.102 \\
(-2.5) \\
\end{array}$ & $\begin{array}{c}-0.405 \\
(-1.4) \\
\end{array}$ & $\begin{array}{c}-0.312 \\
(-1.7) \\
\end{array}$ & $\begin{array}{c}-0.563 \\
(-1.8) \\
\end{array}$ & $\begin{array}{c}-0.605 \\
(-2.9) \\
\end{array}$ \\
\hline \multicolumn{7}{|c|}{ Panel C } \\
\hline$\alpha$ & $\begin{array}{c}-0.297 \\
(-0.2)\end{array}$ & $\begin{array}{c}20.050 \\
(3.5)\end{array}$ & $\begin{array}{l}7.527 \\
(2.4)\end{array}$ & $\begin{array}{l}9.277 \\
(3.8)\end{array}$ & $\begin{array}{l}5.835 \\
(4.9)\end{array}$ & $\begin{array}{l}5.963 \\
(5.9)\end{array}$ \\
\hline$I_{B}$ & $\begin{array}{l}1.057 \\
(0.4)\end{array}$ & $\begin{array}{c}-9.022 \\
(-1.2)\end{array}$ & $\begin{array}{c}-7.475 \\
(-2.2)\end{array}$ & $\begin{array}{c}0.634 \\
(0.2)\end{array}$ & $\begin{array}{c}-0.759 \\
(-0.3)\end{array}$ & $\begin{array}{c}0.554 \\
(0.2)\end{array}$ \\
\hline$\hat{\sigma}_{m}^{2}$ & $\begin{array}{c}0.136 \\
(0.2)\end{array}$ & $\begin{array}{l}-0.211 \\
(-1.1)\end{array}$ & $\begin{array}{c}-0.503 \\
(-1.2)\end{array}$ & $\begin{array}{c}-0.047 \\
(-0.7)\end{array}$ & $\begin{array}{c}-0.756 \\
(-1.8)\end{array}$ & $\begin{array}{c}-0.585 \\
(-3.0)\end{array}$ \\
\hline$R_{m}^{e}$ & $\begin{array}{c}0.278 \\
(2.1)\end{array}$ & $\begin{array}{l}0.522 \\
(4.3)\end{array}$ & $\begin{array}{l}0.429 \\
(4.0)\end{array}$ & $\begin{array}{c}0.299 \\
(6.3)\end{array}$ & $\begin{array}{c}0.201 \\
(3.0)\end{array}$ & $\begin{array}{c}0.104 \\
(2.3)\end{array}$ \\
\hline$I_{B} R_{m}^{e}$ & $\begin{array}{c}-0.385 \\
(-2.8)\end{array}$ & $\begin{array}{l}-0.712 \\
(-4.4)\end{array}$ & $\begin{array}{l}-1.045 \\
(-8.0)\end{array}$ & $\begin{array}{c}-0.549 \\
(-6.6)\end{array}$ & $\begin{array}{c}-0.374 \\
(-2.7)\end{array}$ & $\begin{array}{c}-0.267 \\
(-2.8)\end{array}$ \\
\hline$\hat{\sigma}_{m}^{2} R_{m}^{e}$ & $\begin{array}{c}-55.971 \\
(-0.8) \\
\end{array}$ & $\begin{array}{l}-8.820 \\
(-2.2)\end{array}$ & $\begin{array}{c}-9.702 \\
(-0.8) \\
\end{array}$ & $\begin{array}{c}-2.001 \\
(-1.7) \\
\end{array}$ & $\begin{array}{c}-23.842 \\
(-1.2) \\
\end{array}$ & $\begin{array}{c}-8.605 \\
(-1.5) \\
\end{array}$ \\
\hline \multicolumn{7}{|c|}{ Panel D } \\
\hline$\alpha$ & $\begin{array}{c}0.218 \\
(0.2)\end{array}$ & $\begin{array}{c}13.803 \\
(3.7)\end{array}$ & $\begin{array}{c}3.419 \\
(1.8)\end{array}$ & $\begin{array}{l}9.240 \\
(4.7)\end{array}$ & $\begin{array}{l}4.766 \\
(5.1)\end{array}$ & $\begin{array}{l}4.853 \\
(5.6)\end{array}$ \\
\hline$I_{B \sigma^{2}}$ & $\begin{array}{c}0.026 \\
(0.0)\end{array}$ & $\begin{array}{c}-4.808 \\
(-1.2)\end{array}$ & $\begin{array}{c}-4.655 \\
(-2.1)\end{array}$ & $\begin{array}{c}-2.683 \\
(-1.2)\end{array}$ & $\begin{array}{l}-2.308 \\
(-1.8)\end{array}$ & $\begin{array}{c}-4.056 \\
(-2.8)\end{array}$ \\
\hline$R_{m}^{e}$ & $\begin{array}{c}0.263 \\
(1.9)\end{array}$ & $\begin{array}{l}0.772 \\
(5.0)\end{array}$ & $\begin{array}{l}0.672 \\
(3.0)\end{array}$ & $\begin{array}{c}0.384 \\
(5.9)\end{array}$ & $\begin{array}{c}0.238 \\
(2.0)\end{array}$ & $\begin{array}{c}0.128 \\
(2.0)\end{array}$ \\
\hline$I_{B} R_{m}^{e}$ & $\begin{array}{c}-0.281 \\
(-0.8)\end{array}$ & $\begin{array}{l}-1.207 \\
(-4.8)\end{array}$ & $\begin{array}{c}-1.293 \\
(-5.0)\end{array}$ & $\begin{array}{c}-0.669 \\
(-6.4)\end{array}$ & $\begin{array}{c}-0.424 \\
(-2.3)\end{array}$ & $\begin{array}{c}-0.303 \\
(-2.7)\end{array}$ \\
\hline$\hat{\sigma}_{m}^{2} R_{m}^{e}$ & $\begin{array}{c}-46.141 \\
(-0.6)\end{array}$ & $\begin{array}{c}-18.887 \\
(-3.4)\end{array}$ & $\begin{array}{c}-60.175 \\
(-1.4)\end{array}$ & $\begin{array}{c}-8.332 \\
(-2.4)\end{array}$ & $\begin{array}{c}-49.075 \\
(-0.7)\end{array}$ & $\begin{array}{c}-22.030 \\
(-1.0)\end{array}$ \\
\hline$I_{B \sigma^{2}} R_{m}^{e}$ & $\begin{array}{c}-0.105 \\
(-0.3)\end{array}$ & $\begin{array}{c}0.344 \\
(2.5)\end{array}$ & $\begin{array}{c}0.268 \\
(1.3)\end{array}$ & $\begin{array}{c}0.222 \\
(1.9)\end{array}$ & $\begin{array}{c}0.074 \\
(0.4)\end{array}$ & $\begin{array}{c}0.095 \\
(0.6)\end{array}$ \\
\hline
\end{tabular}


These results are largely consistent with those found for US equities and for all other international equity markets, too. In addition to providing more robustness, these findings also make it more difficult to reconcile under a Merton (1974)-style theory, which is better suited for equity returns.

\subsection{Dynamic Strategies in Other Markets and Asset Classes}

Given the robustness of the option-like features to momentum in other equity markets and other asset classes, we examine the efficacy of dynamic momentum strategies that use these insights in those other markets to see how robust its outperformance is out of sample.

We form the dynamic momentum strategy as before using the ex-ante expected return and volatility of the WML portfolio in each market using the instruments from the previous analysis - the interaction of the ex-ante bear market indicator for that asset class, $I_{B, t-1}$, and the asset-class market volatility over the preceding 6 -months - to forecast the conditional expected return and volatility. Precise specifications of the forecasting model and the GARCH model parameters for each asset class are given in Appendix D.

Panel A of Table 10 reports the Sharpe ratio and skewness (in parentheses) of the simple $\$ 1$ long-\$1 short WML momentum strategy in each market and asset class, as well as a constant volatility momentum strategy and the dynamic momentum strategy as described above. In addition, we report global combinations of the equity momentum strategies across all markets (GE), the non-equity asset classes (GA), and a combination of all equity markets and nonequity asset classes (GAll).

As Panel A of Table 10 shows, there is a marked improvement in Sharpe ratio going from the static WML momentum strategy to a constant volatility momentum strategy to our dynamic momentum strategy in every single market and asset class we study. In most cases, our dynamic strategy doubles the Sharpe ratio over the traditional static momentum portfolio. Furthermore, our dynamic momentum strategy resurrects positive returns in markets where the typical momentum portfolio has failed to produce positive profits, such as Japan. In Japan, the static, classic momentum portfolio delivers a 0.07 Sharpe ratio, but our dynamic momentum portfolio in Japan produces a 0.42 Sharpe ratio. (Alas, even the dynamic strategy does not deliver a significant Sharpe ratio for fixed income.) 


\section{Table 10: Dynamic and Constant Volatility Momentum Across Asset Classes}

Panel A presents the annualized Sharpe ratios of monthly momentum strategies in each of the different asset classes and markets we study. For each asset class, WML denotes the baseline $\$ 1$-long $/ \$ 1$-short static momentum strategy, "cvol" denotes the strategy which is weighted by the ex-ante forecast volatility of the strategy, using daily returns over the prior six months to estimate volatility, and "dyn" is the maximum sharpe ratio strategy described in Appendix C, which dynamically weights the momentum strategy by the conditional Sharpe ratio using ex-ante forecasts of the conditional mean and variance of the momentum strategy's returns using our market stress indicators and past six months volatility estimates. An * indicates a "fully dynamic" implementation where the weighted combination of the dynamic strategies themselves is also employed to aggregate up to the global equity (GE), global asset class, (GA), and global all (Gall), strategies that combine strategies across regions and asset classes. For all other global combinations, each of the component strategies is scaled to have equal volatility, and then the strategies are equally weighted. Panel B reports the intercepts or alphas and their $t$-statistics from spanning regressions of the cvol and optimal dynamic (dyn) portfolios in each market and asset class on the static WML momentum strategy and on each other, within each market and asset class. Each spanning regression also includes the market portfolio for that asset class and the interactions of the market portfolio with the panic state indicator $I_{B \sigma^{2}}$ for each asset class to capture conditional variation in the betas.

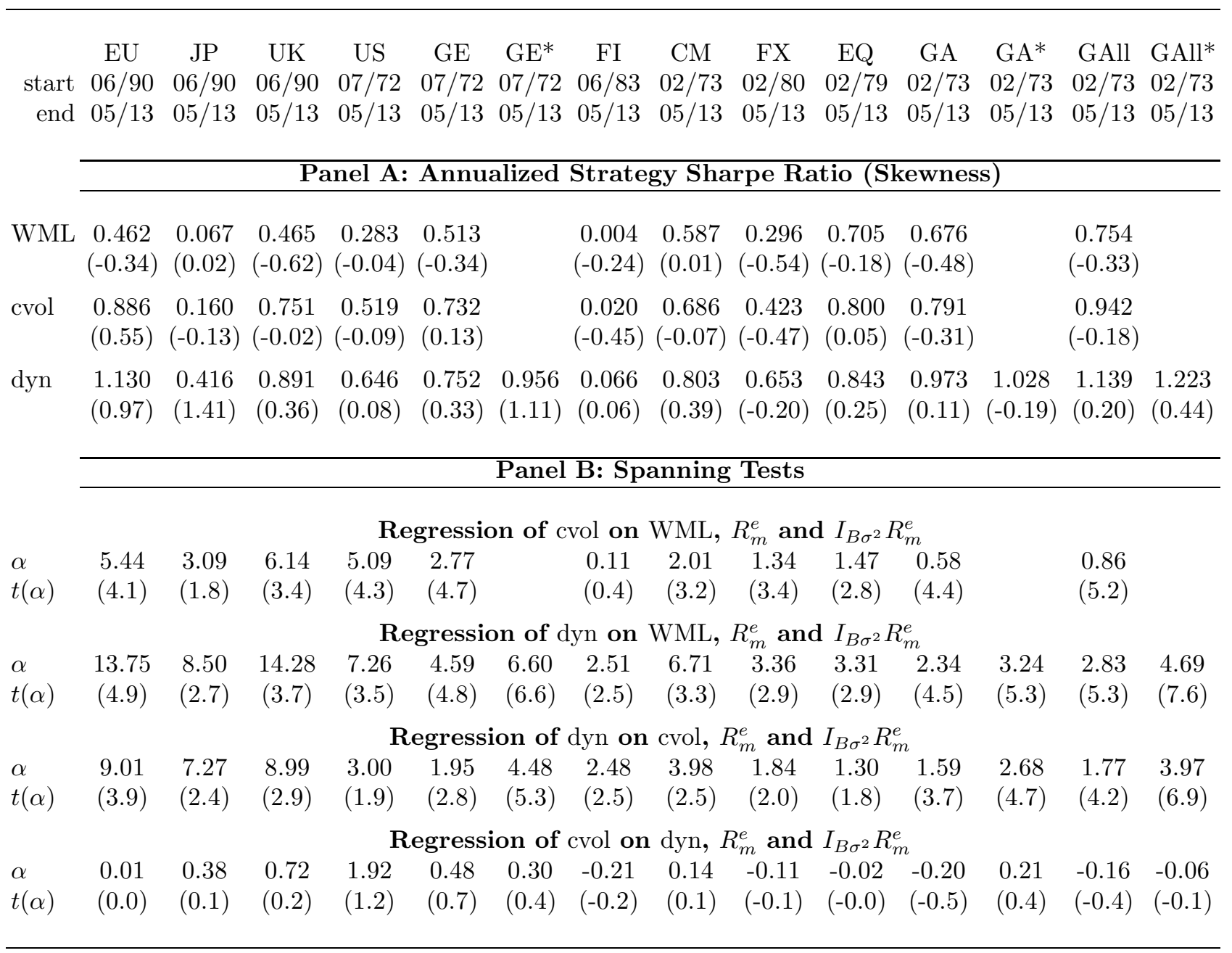


The skewness numbers (in parentheses) are also interesting as the predominantly negative skewness of the static momentum strategies across all markets is apparent, but the dynamic momentum strategies deliver mostly positive skewness - consistent with amelioration of the "crashes" we see in plots of the returns to these strategies.

We also report results for a "fully dynamic" portfolio that is a weighted combination of the individual asset class or market dynamic strategies, where the weighs are based on the ex-ante conditional volatility of each component strategy. That is, each of the component strategies is scaled to have equal volatility (ex ante), and then the strategies are equally weighted. In this way, we are also using cross-sectional information on the strength of the dynamic signal of each component strategy to build a fully dynamic combination portfolio across all asset classes. We denote these fully dynamic strategies with $\mathrm{a}^{*}$ in Table 10. As the table indicates, there is additional Sharpe ratio improvement from this additional twist on our dynamic momentum strategies, providing another robustness test on the use of conditional mean and variance forecastability in enhancing the returns to momentum strategies.

Panel B of Table 10 reports results from spanning tests of the static WML portfolio, the constant volatility strategy, and the dynamic strategy within each market and asset class. These daily return regressions also include interactions of the excess market return and the excess market return (for that asset class) interacted with the asset-class specific panic state indicator $I_{B \sigma^{2}}$ to capture conditional variation in the betas. ${ }^{12}$ The first row reports alphas (and their $t$-statistics) of the constant volatility strategy on WML in each market and asset class, as well as globally across equity markets (GE), asset classes (GA), and all markets and asset classes (Gall). Consistent with the results of Barroso and Santa-Clara (2012) for US equities, the constant volatility strategy delivers positive alpha relative to the static momentum strategy in every single market and asset class that is highly significant (except Japan and fixed income, where momentum does not yield statistically significant positive returns to begin with).

The second row reports alphas of the dynamic momentum strategy with respect to WML. Here too, the alphas are all positive and statistically significant, and in every single market and asset class are larger than the constant volatility momentum alphas. Since both the dynamic and constant volatility strategies are scaled to the same volatility, this suggests that

\footnotetext{
${ }^{12}$ As with our spanning tests in Section 4, the dynamic strategy used in Panel B is based on ex-ante forecasts of the mean and variance of the residual from a regression of the WML strategy on the excess market return $R_{m}^{e}$ and the interacted market return $I_{B \sigma^{2}} R_{m}^{e}$, using the panic state indicator and lagged residual variances as forecasting variables. See footnote 9 .
} 
the dynamic momentum portfolio offers improved mean-variance efficiency over the constant volatility portfolio.

To test this notion more formally, the last two sets of rows of Panel B of Table 10 report the alphas from regressions of the dynamic strategy returns on the constant volatility strategy returns, and vice-versa. The results are consistent with our previous findings: in virtually every market and asset class the dynamic momentum portfolio delivers positive and statistically significant alpha relative to the constant volatility strategy, suggesting that the constant volatility strategy does not span the dynamic strategy in any market or asset class. Conversely, in every market and asset class the constant volatility strategy fails to produce a significant alpha with respect to the dynamic strategy, suggesting that the dynamic momentum strategy spans the constant volatility strategy in every market and asset class. These results, shown out of sample in eight other markets and asset classes, make a compelling case for the robustness of the dynamic momentum portfolio based on the optionality insights of momentum strategies in every market.

Overall, the consistent evidence of the optionality of momentum strategies, conditional betas and return premia, and the significant improvement from our dynamic weighting scheme across many different markets and vastly different asset classes, provides a wealth of out of sample evidence. Momentum crashes and their forecastability by bear market and ex-ante volatility measures are a reliable and robust feature of momentum strategies that may provide clues as to the underlying source of this return factor. ${ }^{13}$

\section{Conclusions}

In "normal" environments we see consistent price momentum that is both statistically and economically strong and manifests itself across numerous equity markets and a wide range of diverse asset classes.

However, in extreme market environments following a long market downturn, the market prices of past losers embody a very high premium. When poor market conditions ameliorate and

\footnotetext{
${ }^{13}$ Although beyond the scope of this paper, it would be interesting to see if other momentum-type strategies, such as earnings momentum in equities (Chan, Jegadeesh, and Lakonishok (1996)), or time-series momentum in futures contracts (Moskowitz, Ooi, and Pedersen (2012)), or cross-momentum effects (Cohen and Frazzini (2008)) exhibit similar features.
} 
the market starts to rebound, the losers experience strong gains, resulting in a "momentum crash" as momentum strategies short these assets. We find that, in bear market states, and in particular when market volatility is high, the down-market betas of the past-losers are low, but the up-market betas are very large. This optionality does not appear to generally be reflected in the prices of the past losers. Consequently, the expected returns of the past losers are very high, and the momentum effect is reversed during these times. This feature does not apply equally to winners during good times, however, resulting in an asymmetry in the winner and loser exposure to market returns during extreme times.

These results are shown to be robust across eight different markets and asset classes, as well as multiple time periods. Moreover, these crash periods are predictable: we use bear market indicators and ex-ante volatility estimates to forecast the conditional mean and variance of momentum strategies. Armed with these estimates, we create a simple dynamically-weighted version of the momentum portfolio that approximately doubles the Sharpe ratio of the static momentum strategy and is not spanned by constant volatility momentum strategies or other factors - doing so consistently in every market, asset class, and time period we study.

What can explain these findings? We examine a variety of explanations ranging from compensation for crash risk to volatility risk, to other factor risks such as the Fama and French (1993) factors, but find that none of these explanations can account fully for our findings. For equity momentum, a Merton (1974) story for the option-like payoffs of equities may make sense, but the existence of the same phenomena and option-like features for momentum strategies in futures, bonds, currencies, and commodities, makes this story more challenging. Alternatively, these effects may be loosely consistent with several behavioral findings, where in extreme situations individuals tend to be fearful and appear to focus on losses, largely ignoring probabilities. ${ }^{14}$ Whether this behavioral phenomenon is fully consistent with the empirical results documented here is a subject for further research and would indicate that the behavior of market participants in each of these markets and asset classes is affected similarly, despite the fact that the average and marginal investor in these various markets are likely to be quite different along many other dimensions.

\footnotetext{
${ }^{14}$ See Sunstein and Zeckhauser (2008), Loewenstein, Weber, Hsee, and Welch (2001), and Loewenstein $(2000)$.
} 


\section{Appendices}

\section{A Detailed Description of Calculations}

\section{A.1 Cumulative Return Calculations}

The cumulative return, on an (implementable) strategy is an investment at time 0, which is fully reinvested at each point - i.e., where no cash is put in or taken out. That is, the cumulative arithmetic returns between times $t$ and $T$ is denoted $R(t, T)$.

$$
R(t, T)=\prod_{s=t+1}^{T}\left(1+R_{s}\right)-1
$$

where $R_{s}$ denotes the arithmetic return in the period ending at time $t$, and $r_{s}=\log \left(1+R_{s}\right)$ denotes the log-return over period $s$,

$$
r(t, T)=\sum_{s=t+1}^{T} r_{s} .
$$

For long-short portfolios, the cumulative return is:

$$
R(t, T)=\prod_{s=t+1}^{T}\left(1+R_{L, s}-R_{S, s}+R_{f, t}\right)-1,
$$

where the terms $R_{L, s}, R_{S, s}$, and $R_{f, s}$ are, respectively, the return on the long side of the portfolio, the short side of the portfolio, and the risk-free rate. Thus, the strategy reflects the cumulative return, with an initial investment of $V_{t}$, which is managed in the following way:

1. Using the $\$ V_{0}$ as margin, you purchase $\$ V_{0}$ of the long side of the portfolio, and short $\$ V_{0}$ worth of the short side of the portfolio. Note that this is consistent with Reg-T requirements. Over each period $s$, the margin posted earns interest at rate $R_{f, s}$.

2. At then end of each period, the value of the investments on the long and the short side of the portfolio are adjusted to reflect gains to both the long and short side of the portfolio. So, for example, at the end of the first period, the investments in both the long and short side of the portfolio are adjusted to set their value equal to the total value of the portfolio to $V_{t+1}=V_{t} \cdot\left(1+R_{L}-R_{S}+R_{f}\right)$.

This methodology assumes that there are no margin calls, etc., except at the end of each month. These calculated returns do not incorporate transaction costs. 


\section{A.2 Calculation of Variance Swap Returns}

We calculate the returns to a daily variance swap on the S\&P 500 using daily observations on the SPX and the VIX, and daily levels of the one-month Treasury bill rate. The historical daily observations on the SPX and the VIX, beginning on January 2, 1990, are taken from the CBOE's VIX website. ${ }^{15}$ The daily one-month interest rate series is taken from Ken French's data library.

The VIX is calculated using a panel of S\&P 500 index options with a wide range of strike prices and with two maturity dates - generally the two closest-to-maturity contracts, weighted in such a way so as to most closely approximate the swap rate for a variance swap with a constant maturity of 30 calendar days. ${ }^{16}$ The calculation method used by the CBOE makes the VIX equivalent to the swap rate for a variance swap on the S\&P 500 over the coming 30 calendar days. However, the methodology used by the CBOE is to: (1) annualize this variance; (2) take the square-root of the variance (to convert to volatility), multiply by 100 to convert to percentage terms.

Given the VIX construction methodology, we can calculate the daily return on a variance swap, from day $t-1$ to day $t$, as:

$$
R_{v s, t}=D_{t}\left[\frac{1}{21}\left(252\left[100 \cdot \log \left(\frac{S_{t}}{S_{t-1}}\right)\right]^{2}-\mathrm{VIX}_{t-1}^{2}\right)+\frac{20}{21}\left(\mathrm{VIX}_{t}^{2}-\mathrm{VIX}_{t-1}^{2}\right)\right]
$$

Here $D_{t}$ is the 20-trading day discount factor. This is calculated as $D_{t}=\left(1+r_{1 m, t}\right)^{20 / 252}$, where $r_{1 m, t}$ is the annualized one-month treasury bill yield as of day $t$, from Ken French's

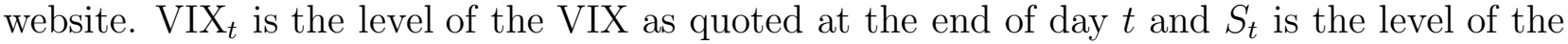
$\mathrm{S} \& \mathrm{P} 500$, adjusted for all corporate actions, at the end of day $t$. Note that the factors of 252 and 100 in the equation are because the VIX is quoted in annualized, percentage terms.

This equation is given a flat forward variance curve. That is, we are implicitly making the assumption that the swap rate on 20 trading-day and 21 trading-day variance swap rates on day $t$ are identical (and equal to $\operatorname{VIX}_{t}^{2}$ ). For the market, this approximation should be fairly accurate.

\section{B Exposure to and of Size and Value Factors}

We regress the WML momentum portfolio returns on the three Fama and French (1993) factors consisting of the CRSP VW index return in excess of the risk-free rate, a small minus big (SMB) stock factor, and a high BE/ME minus low BE/ME (HML) factor, all obtained

\footnotetext{
${ }^{15}$ The daily data for the new VIX are available at http://www. cboe.com/micro/VIX/historical .aspx.

${ }^{16}$ See Chicago Board Options Exchange (2003) for a full description of the VIX calculation.
} 


\section{Table 11: Conditional Estimation of WML, HML, and SMB premia}

This table presents the results of monthly time-series regressions. The dependent variable is indicated at the head of each column, and is either: (1) WML; (2) the $H M L$-devil portfolio proposed by Asness and Frazzini (2011); the SMB portfolio return of Fama and French (1993); or (4) a portfolio which is 50\% WML and $50 \% H M L$-devil. The independent variables are: intercept $\alpha$, the normalized ex-ante forecasting variable $\mathrm{I}_{B \sigma^{2}} \equiv\left(1 / \bar{v}_{B}\right) \mathrm{I}_{B, t-1} \cdot \hat{\sigma}_{m}^{2}$, and this forecasting variable interacted with the excess market return and the Fama and French (1993) HML and SMB returns. The sample is January 1927 through March, 2013 for the WML and SMB regressions, and January 1927-December 2012 for the HML-d and WML+HML-d portfolios. The coefficients for $\alpha$ and $I_{B, t-1} \hat{\sigma}_{m}^{2}$ are converted to annualized, percentage terms by multiplying by $12 \times 100$.

\begin{tabular}{|c|c|c|c|c|c|c|c|c|}
\hline \multirow{3}{*}{$\begin{array}{l}\text { Vars. } \\
\alpha\end{array}$} & \multicolumn{8}{|c|}{ Dependent Variable - Return Series } \\
\hline & \multicolumn{2}{|c|}{ WML } & \multicolumn{2}{|c|}{ HML-d } & \multicolumn{2}{|c|}{ SMB } & \multicolumn{2}{|c|}{$\overline{\text { WML+HML-d }}$} \\
\hline & $\begin{array}{c}24.93 \\
(8.6)\end{array}$ & $\begin{array}{c}26.95 \\
(9.4)\end{array}$ & $\begin{array}{l}2.96 \\
(1.8)\end{array}$ & $\begin{array}{l}3.14 \\
(2.2)\end{array}$ & $\begin{array}{l}1.91 \\
(1.5)\end{array}$ & $\begin{array}{c}0.34 \\
(0.3)\end{array}$ & $\begin{array}{l}13.41 \\
(10.0)\end{array}$ & $\begin{array}{c}14.08 \\
(11.0)\end{array}$ \\
\hline$I_{B \sigma^{2}}$ & $\begin{array}{r}-28.80 \\
(-5.8)\end{array}$ & $\begin{array}{c}-26.94 \\
(-5.4)\end{array}$ & $\begin{array}{l}9.32 \\
(3.3)\end{array}$ & $\begin{array}{l}6.57 \\
(2.7)\end{array}$ & $\begin{array}{l}5.33 \\
(2.4)\end{array}$ & $\begin{array}{l}5.44 \\
(2.6)\end{array}$ & $\begin{array}{c}-12.01 \\
(-5.2)\end{array}$ & $\begin{array}{c}-11.13 \\
(-5.1)\end{array}$ \\
\hline$r_{m}^{e}$ & $\begin{array}{l}-0.17 \\
(-3.3)\end{array}$ & $\begin{array}{l}-0.15 \\
(-2.7)\end{array}$ & & $\begin{array}{l}-0.02 \\
(-0.6)\end{array}$ & & $\begin{array}{l}0.21 \\
(9.4)\end{array}$ & & $\begin{array}{l}-0.09 \\
(-4.0)\end{array}$ \\
\hline$I_{B \sigma^{2}} \cdot r_{m}^{e}$ & $\begin{array}{c}-0.54 \\
(-12.9)\end{array}$ & $\begin{array}{l}-0.44 \\
(-7.8)\end{array}$ & & $\begin{array}{c}0.33 \\
(16.3)\end{array}$ & & $\begin{array}{l}-0.01 \\
(-0.4)\end{array}$ & & $\begin{array}{l}-0.11 \\
(-5.8)\end{array}$ \\
\hline$r_{\mathrm{SMB}}$ & & $\begin{array}{l}-0.16 \\
(-1.9)\end{array}$ & & & & & & \\
\hline$I_{B \sigma^{2}} \cdot r_{\mathrm{SMB}}$ & & $\begin{array}{l}-0.18 \\
(-2.2)\end{array}$ & & & & & & \\
\hline$r_{\mathrm{HML}}$ & & $\begin{array}{l}-0.38 \\
(-4.8)\end{array}$ & & & & & & \\
\hline$I_{B \sigma^{2}} \cdot r_{\mathrm{HML}}$ & & $\begin{array}{l}0.05 \\
(0.7)\end{array}$ & & & & & & \\
\hline
\end{tabular}

from Ken French's website. In addition, we interact each of the factors with the panic state variable $I_{B \sigma^{2}}$. The results are reported in Table 11, where the abnormal performance of momentum continues to be significantly more negative in bear market states, whether we measure abnormal performance relative to the market model or to the Fama and French (1993) three-factor model, with little difference in the point estimates.

The next two columns of the table repeat the market model regressions using HML as the dependent variable instead of WML. For these regressions, we use the modified HML portfolio of Asness and Frazzini (2011). Specifically, Asness and Frazzini show that the Fama and French (1993) HML construction, by using lagged market prices in its BE/ME calculations, inherently induces some positive covariance with momentum. They advocate using the most recent (last month's) price to compute BE/ME ratios in constructing their HML factor, which they term HML-devil (HML-d), in order to examine the value effect separately from momentum. As Table 11 shows, the abnormal return of the HML portfolio increases in the panic states, the opposite of what we find for momentum. This is not surprising for several reasons. First, momentum strategies buy past winners and sell past losers, while value strategies typically buy 
longer-term past losers and sell winners (see DeBondt and Thaler (1987) and Fama and French (1996)). Also, the correlation between HML-d and UMD is approximately -0.50. Finally, this result is consistent with the intuition for why the market-beta of the WML portfolio changes with past market-returns. Since growth (low book-to-price) stocks have generally had high past returns and value stocks low past returns, the same intuition suggests that HML's beta should be high when $I_{B, t-1}=1$, and it is. Specifically, HML's market beta is higher by 0.33 when $I_{B, t-1}=1(t$-stat $=16.3)$, as indicated by the interaction term. More directly, the correlation of HML with the excess return on the market during panic states is 0.59 , but during normal times it is -0.10 . Conversely, for the WML portfolio, the correlation with the market is 0.02 during normal times and -0.71 when $\mathrm{I}_{B, t-1}=1$.

The next two columns of Table 11 repeat this exercise using SMB as the dependent variable. The premium on SMB is statistically significantly higher in panic states as well, but its beta does not change significantly during these states. This makes sense since size is a poor proxy for recent short-term performance.

Finally, the last two columns run regressions for a 50-50 equal combination of WML and HML-d following Asness, Moskowitz, and Pedersen (2013), who show that a combination of value and momentum diversifies away a variety of exposures including aggregate market and liquidity risks. Given the opposite-signed results for WML and HML-d on the panic state variables, it is not surprising that a combination of WML and HML-d hedges some of this risk. However, since the magnitude of the effects on WML are much larger than those of $\mathrm{HML}$, the net effect is still a reduction in returns and a decrease in beta during panic states for the momentum-value combination. ${ }^{17}$

\section{Maximum Sharpe Ratio Strategy}

The setting is discrete time with $T$ periods from $1, \ldots, T$. We can trade in two assets, a risky asset and a risk free asset. Our objective is to maximize the Sharpe ratio of a portfolio where, each period, we can trade in or out of the risky asset with no cost.

Over period $t+1-$ which is the span from $t$ to $t+1$ - the excess return on a risky asset $\tilde{r}_{t+1}$ is distributed normally, with time- $t$ conditional mean $\mu_{t}$ and conditional variance $\sigma_{t}^{2}$. That is,

$$
\mu_{t}=\mathbb{E}_{t}\left[\tilde{r}_{t+1}\right] \text { and } \sigma_{t}^{2}=\mathbb{E}_{t}\left[\left(\tilde{r}_{t+1}-\mu_{t}\right)^{2}\right]
$$

Suppose further that at $t=0$ the agent knows $\mu_{t}$ and $\sigma_{t}$ for $t \in\{0, \ldots, T-1\}$.

The agent's objective is to maximize the full period Sharpe ratio of a managed portfolio. The agent manages the portfolio by placing, at the beginning of each period, a fraction $w_{t}$ of the

\footnotetext{
${ }^{17}$ One possibility for the dominance of momentum here is that the 50-50 momentum-value weighting is based on equal dollar allocation to both rather than equal risk allocation. Since momentum is more volatile than value, this may be tilting the overall exposure of the combination portfolio more toward momentum.
} 
value of the managed portfolio in the risky asset, and a fraction $1-w_{t}$ in the risk-free asset. The time $t$ expected excess return and variance of the managed portfolio in period $t+1$ is then given by:

$$
\tilde{r}_{p, t+1}=w_{t} \tilde{r}_{t+1} \sim \mathcal{N}\left(w_{t} \mu_{t}, w_{t}^{2} \sigma_{t}^{2}\right) .
$$

The Sharpe ratio over the $T$ periods is:

$$
\mathrm{SR}=\frac{\mathbb{E}\left[\frac{1}{T} \sum_{t=1}^{T} \tilde{r}_{p, t}\right]}{\sqrt{\mathbb{E}\left[\frac{1}{T} \sum_{t=1}^{T}\left(\tilde{r}_{p, t}-\bar{r}_{p}\right)^{2}\right]}}
$$

where the $\bar{r}_{p}$ in the denominator is the sample average per period excess return $\left(\frac{1}{T} \sum_{t=1}^{T} \tilde{r}_{p, t}\right)$.

Given the information structure of this optimization problem, maximizing the Sharpe ratio is equivalent to solving the constrained maximization problem:

$$
\max _{w_{0}, \ldots, w_{T-1}} \mathbb{E}\left[\frac{1}{T} \sum_{t=1}^{T} \tilde{r}_{p, t}\right] \quad \text { subject to } \mathbb{E}\left[\frac{1}{T} \sum_{t=1}^{T}\left(\tilde{r}_{p, t}-\bar{r}\right)^{2}\right]=\sigma_{p}^{2} .
$$

If the period length is sufficiently short, then $\mathbb{E}\left[\left(\tilde{r}_{p, t}-\bar{r}\right)^{2}\right] \approx \sigma_{t}^{2}=\mathbb{E}_{t}\left[\left(\tilde{r}_{t+1}-\mu_{t}\right)^{2}\right]$. With this approximation, substituting in the conditional expectations for the managed portfolio from equation (10) gives the Lagrangian:

$$
\max _{w_{0}, \ldots, w_{T-1}} \mathscr{L} \equiv \max _{w_{t}}\left(\frac{1}{T} \sum_{t=0}^{T-1} w_{t} \mu_{t}\right)-\lambda\left(\frac{1}{T} \sum_{t=0}^{T-1} w_{t}^{2} \sigma_{t}^{2}=\sigma_{p}^{2}\right) .
$$

The $T$ first order conditions for optimality are:

$$
\left.\frac{\partial \mathscr{L}}{\partial w_{t}}\right|_{w_{t}=w_{t}^{*}}=\frac{1}{T}\left(\mu_{t}-2 \lambda w_{t}^{*} \sigma_{t}^{2}\right)=0 \quad \forall t \in\{0, \ldots, T-1\}
$$

giving an optimal weight on the risky asset at time $t$ of:

$$
w_{t}^{*}=\left(\frac{1}{2 \lambda}\right) \frac{\mu_{t}}{\sigma_{t}^{2}}
$$

That is, the weight placed on the risky asset at time $t$ should be proportional to the expected excess return over the next period, and inversely proportional to the conditional variance.

\section{GJR-GARCH Forecasts of Momentum Volatility}

The construction of the dynamic portfolio strategy we explore in Sections 4 and 5.4 requires estimates of the conditional mean return and the conditional volatility of the momentum 
strategies. To forecast the volatility we first fit a GARCH process to the daily momentum returns of each asset class. Specifically, we fit the GARCH model proposed by Glosten, Jagannathan, and Runkle (1993), and summarized by equations (6) and (7). The maximum likelihood estimates and $t$-statistics are:

\begin{tabular}{rccccc} 
parameter: & $\hat{\mu}$ & $\hat{\omega}$ & $\hat{\alpha}$ & $\hat{\gamma}$ & $\hat{\beta}$ \\
\hline ML-est & $0.86 \times 10^{-3}$ & $1.17 \times 10^{-6}$ & 0.111 & -0.016 & 0.896 \\
$t$-stat & $(14.7)$ & $(4.2)$ & $(14.4)$ & $(-1.6)$ & $(85.1)$
\end{tabular}

We then regress the future realized 22-day WML return volatility $\hat{\sigma}_{22, t+1}$ on the GJR-GARCH estimate $\left(\hat{\sigma}_{\mathrm{GARCH}, \mathrm{t}}\right)$ and the lagged 126 -day WML return volatility $\left(\hat{\sigma}_{126, t}\right)$, and a constant. The OLS coefficient estimates and $t$-statistics are:

\begin{tabular}{rccc} 
coefficient: & $\hat{\alpha}$ & $\hat{\sigma}_{\mathrm{GARCH}, \mathrm{t}}$ & $\hat{\sigma}_{126, t}$ \\
\hline coef. est. & 0.0010 & 0.6114 & 0.2640 \\
t-stat & $(3.0)$ & $(16.7)$ & $(7.2)$
\end{tabular}

with a regression $R_{\text {adj }}^{2}=0.617 .{ }^{18}$ The fitted estimate of $\hat{\sigma}_{22, t+1}$ is then used as an input to the dynamic WML portfolio weight, as discussed in Sections 4 and 5.4.

The same estimation procedure is used to generate a forecast of the future 22-day WML return volatility in each of the alternative asset classes. The maximum-likelihood GJR-GARCH parameter estimates and $t$-statistics, and regression estimates and $t$-statistics are presented in Table 12.

The parameters above and in Table 12 tell an interesting story: first, in the regressions, the coefficient on the GJR-GARCH estimate of volatility is always significant, and the coefficient on the lagged 126-day volatility is always smaller, but not always statistically significant. There appears to be a longer-lived component of volatility that $\hat{\sigma}_{126, t}$ is capturing.

Also interesting is the leverage parameter $\gamma$. In each of the asset classes, the maximumlikelihood estimate of $\gamma$ is negative: this means that a strong negative return on the WML portfolio is generally associated with a decrease in the WML return variance. As noted elsewhere in the literature, this coefficient is positive at high levels of statistical significance for the market return (see, e.g., Glosten, Jagannathan, and Runkle (1993) and Engle and Ng (1993).)

\footnotetext{
${ }^{18}$ The lag one residual autocorrelation is $0.013(t$-stat $=0.44)$, justifying the use of OLS standard errors. Also, the $t$-statistics on the lag 2-5 autocorrelations never exceed 1.14. It is interesting that the autocorrelation of the dependent variable of the regression $\left(\hat{\sigma}_{22, t}\right)$ is large and statistically significant $\left(\hat{\rho}_{1}=0.55, t\right.$-stat $\left.=24.5\right)$. This suggests that the autocorrelation in $\hat{\sigma}_{22, t}$ results from its forecastable component. The residual from its projection on the forecast variables is uncorrelated at any conventional statistically significant level.
} 


\section{Table 12: Maximum Likelihood Estimates of GJR-GARCH Model for Momentum Portfolios}

The upper panel of this table presents the maximum likelihood estimates of the coefficients of the GJR-GARCH model - given by equations (6) and (7) - fitted to each of the momentum portfolios we examine in Section 5.4. Start and end dates for each of the 11 daily return series are also given in yyyy-mm-dd format. Note that the estimates of the $\mu$ and $\omega$ coefficients are multiplied by $10^{3}$ and $10^{6}$, respectively. Maximum Likelihood based t-statistics are given in parentheses. For $\beta$, this t-statistic tests whether $\beta=1$; for all other parameters it tests whether the parameter is zero. The lower panel presents the results of the monthly regressions in which we regress the future one month daily volatility of the WML portfolio on an intercept $(\alpha)$, on the lagged 126 day WML return volatility $\left(\sigma_{126}\right)$, and on the lagged GJM-GARCH volatility $\left(\sigma_{\mathrm{GARCH}}\right)$.

\begin{tabular}{|c|c|c|c|c|c|c|c|c|c|c|c|}
\hline \multirow{6}{*}{$\begin{array}{r}\text { start } \\
\text { end } \\
\left.\times 10^{3}\right)\end{array}$} & \multicolumn{11}{|c|}{ GARCH estimates by Asset Class } \\
\hline & $\mathrm{EU}$ & JP & UK & US & GLB & FI & $\mathrm{CM}$ & $\mathrm{FX}$ & EQ & GA & GAll \\
\hline & $1990-01-02$ & 1990-01-02 & 1990-01-02 & $1972-02-01$ & $1972-02-01$ & $1983-01-03$ & $1972-02-01$ & $1979-01-01$ & $1978-01-02$ & $1972-02-01$ & $1972-02-01$ \\
\hline & 2013-05-31 & 2013-05-31 & 2013-05-31 & 2013-05-31 & $2013-05-31$ & 2013-06-03 & 2013-06-03 & 2013-06-03 & $2013-06-03$ & 2013-06-03 & 2013-05-31 \\
\hline & 0.387 & 0.187 & 0.316 & 0.314 & 0.124 & 0.024 & 0.516 & 0.238 & 0.322 & 0.154 & 0.159 \\
\hline & $(5.3)$ & $(3.0)$ & $(3.4)$ & $(6.2)$ & $(6.7)$ & $(0.6)$ & $(5.0)$ & $(4.2)$ & $(5.3)$ & $(5.8)$ & $(5.6)$ \\
\hline$\omega\left(\times 10^{6}\right)$ & 0.569 & 0.616 & 0.364 & 0.298 & 0.024 & 0.027 & 1.525 & 0.455 & 0.619 & 0.034 & 0.035 \\
\hline & $(2.4)$ & $(4.3)$ & $(3.3)$ & $(4.1)$ & $(3.3)$ & $(1.4)$ & $(4.1)$ & $(4.3)$ & $(3.9)$ & $(1.6)$ & $(1.6)$ \\
\hline$\alpha$ & 0.089 & 0.160 & 0.094 & 0.104 & 0.107 & 0.060 & 0.055 & 0.092 & 0.074 & 0.037 & 0.046 \\
\hline & $(6.4)$ & $(9.8)$ & $(7.7)$ & $(12.4)$ & (12.1) & $(4.1)$ & $(9.0)$ & $(9.0)$ & $(6.9)$ & $(3.7)$ & $(4.2)$ \\
\hline$\gamma$ & -0.020 & -0.007 & -0.022 & -0.026 & -0.024 & -0.002 & -0.008 & -0.020 & -0.002 & -0.011 & -0.007 \\
\hline & $(-1.6)$ & $(-1.6)$ & $(-2.0)$ & $(-2.8)$ & $(-2.0)$ & $(-1.6)$ & $(-2.3)$ & $(-1.8)$ & $(-1.6)$ & $(-1.6)$ & $(-0.8)$ \\
\hline$\beta$ & 0.912 & 0.848 & 0.918 & 0.907 & 0.909 & 0.945 & 0.940 & 0.909 & 0.916 & 0.966 & 0.955 \\
\hline & $(-5.9)$ & $(-11.4)$ & $(-8.9)$ & $(-11.1)$ & $(-11.4)$ & $(-4.2)$ & $(-8.1)$ & $(-9.6)$ & $(-7.1)$ & $(-2.9)$ & $(-3.2)$ \\
\hline & \multicolumn{11}{|c|}{ Regression estimates by Asset Class } \\
\hline$\alpha\left(\times 10^{2}\right)$ & 0.053 & 0.083 & 0.067 & 0.036 & 0.016 & 0.082 & 0.177 & 0.144 & 0.096 & 0.065 & 0.034 \\
\hline & $(1.3)$ & $(1.8)$ & $(1.4)$ & $(1.5)$ & $(1.5)$ & $(4.7)$ & $(3.0)$ & $(4.4)$ & $(2.8)$ & $(4.0)$ & $(2.8)$ \\
\hline$\hat{\sigma}_{126}$ & 0.334 & 0.126 & 0.159 & 0.227 & 0.280 & 0.475 & 0.161 & 0.125 & 0.233 & 0.113 & 0.180 \\
\hline & $(4.7)$ & $(1.8)$ & $(2.1)$ & $(4.3)$ & $(5.1)$ & $(5.7)$ & $(2.2)$ & $(1.8)$ & $(3.5)$ & $(1.1)$ & $(2.2)$ \\
\hline$\hat{\sigma}_{\mathrm{GARCH}}$ & 0.561 & 0.754 & 0.758 & 0.682 & 0.632 & 0.220 & 0.665 & 0.581 & 0.594 & 0.637 & 0.655 \\
\hline & $(8.0)$ & (11.4) & $(9.9)$ & (13.1) & (11.6) & $(2.9)$ & $(9.1)$ & $(9.3)$ & $(9.2)$ & $(6.1)$ & $(7.9)$ \\
\hline
\end{tabular}




\section{References}

Asness, Cliff, and Andrea Frazzini, 2011, The devil in hml's details, AQR Capital Management Paper.

Asness, Clifford S., 1994, The power of past stock returns to explain future stock returns, Working paper, University of Chicago.

— John M. Liew, and Ross L. Stevens, 1997, Parallels between the cross-sectional predictability of stock and country returns, Journal of Portfolio Management 23, 79-87.

Asness, Clifford S., Toby J. Moskowitz, and Lasse Heje Pedersen, 2013, Value and momentum everywhere, The Journal of Finance 58, 929-895.

Barroso, Pedro, and Pedro Santa-Clara, 2012, Managing the risk of momentum, Nova School of Business and Economics working paper.

Boguth, Oliver, Murray Carlson, Adalai Fisher, and Mikhail Simutin, 2010, Conditional risk and performance evaluation: Volatility timing, overconditioning, and new estimates of momentum alphas, Journal of Financial Economics, forthcoming.

Brunnermeier, Markus K., Stefan Nagel, and Lasse H. Pedersen, 2008, Carry trades and currency crashes, NBER Macroeconomics Annual.

Carr, Peter, and Liuren Wu, 2009, Variance risk premiums, Review of Financial Studies 22, $1311-1341$.

Chabot, Benjamin, Eric Remy, Ghysels, and Ravi Jagannathan, 2009, Momentum cycles and limits to arbitrage - evidence from victorian england and post-depression us stock markets, Working Paper.

Chan, K.C., 1988, On the contrarian investment strategy, Journal of Business 61, 147-163.

Chan, Louis K.C., Narasimhan Jegadeesh, and Josef Lakonishok, 1996, Momentum strategies, Journal of Finance 51, 1681-1714.

Chicago Board Options Exchange, 2003, VIX: CBOE volatility index, CBOE White Paper; www.cboe.com.

Christensen, Bent J, and Nagpurnanand R Prabhala, 1998, The relation between implied and realized volatility, Journal of Financial Economics 50, 125-150.

Cohen, Lauren, and Andrea Frazzini, 2008, Economic links and predictable returns, The Journal of Finance 63, 1977-2011.

Cooper, Michael J., Roberto C. Gutierrez, and Allaudeen Hameed, 2004, Market states and momentum, Journal of Finance 59, 1345-1365. 
DeBondt, Werner F. M., and Richard H. Thaler, 1987, Further evidence on investor overreaction and stock market seasonality, Journal of Finance 42, 557-581.

Engle, Robert F., and Victor K. Ng, 1993, Measuring and testing the impact of news on volatility, Journal of Finance 48, 1749-1778.

Erb, Claude B., and Campbell R. Harvey, 2006, The strategic and tactical value of commodity futures, Financial Analysts Journal 62, 69-97.

Fama, Eugene F., and Kenneth R. French, 1993, Common risk factors in the returns on stocks and bonds, Journal of Financial Economics 33, 3-56.

$55-84$

Geczy, Christopher, and Mikhail Samonov, 2013, 212 years of price momentum (the world's longest backtest: 1801-2012), Octoquant working paper and SSRN \# 2292544.

Glosten, Lawrence R., Ravi Jagannathan, and David Runkle, 1993, On the relation between the expected value and the volatility of the nominal excess return on stocks, Journal of Finance 48, 1779-1801.

Grundy, Bruce, and J. Spencer Martin, 2001, Understanding the nature of the risks and the source of the rewards to momentum investing, Review of Financial Studies 14, 29-78.

Hansen, Lars P., and Ravi Jagannathan, 1991, Implications of security market data for models of dynamic economies, Journal of Political Economy 99, 225-262.

Henriksson, Roy D., and Robert C. Merton, 1981, On market timing and investment performance. II. Statistical procedures for evaluating forecasting skills, Journal of Business 54, $513-533$.

Israel, Ronen, and Tobias J Moskowitz, 2013, The role of shorting, firm size, and time on market anomalies, Journal of Financial Economics 108, 275-301.

Jagannathan, Ravi, and Robert A. Korajczyk, 1986, Assessing the market timing performance of managed portfolio, Journal of Business 59, 217-235.

Jegadeesh, Narasimhan, 1990, Evidence of predictable behavior of security returns, Journal of Finance 45, 881-898.

— tions for stock market efficiency, Journal of Finance 48, 65-91.

- 1995, Overreaction, delayed reaction, and contrarian profits, Review of Financial Studies 8, 973-999.

— , 2001, Profitability of momentum strategies: An evaluation of alternative explanations, Journal of Finance 56, 699-720. 
Kothari, S.P., and Jay Shanken, 1992, Stock return variation and expected dividends, Journal of Financial Economics 31, 177-210.

Lehmann, Bruce N., 1990, Fads, martingales, and market efficiency, Quarterly Journal of Economics 105, 1-28.

Lo, Andrew W., and A. Craig MacKinlay, 1990, When are contrarian profits due to stock market overreaction?, Review of Financial Studies 3, 175-205.

Loewenstein, George, Elke U. Weber, Chris K. Hsee, and Ned Welch, 2001, Risk as Feelings, Psychological bulletin 127, 267-286.

Loewenstein, George F., 2000, Emotions in economic theory and economic behavior, American Economic Review 65, 426-432.

Merton, Robert C., 1974, On the pricing of corporate debt: The risk structure of interest rates, The Journal of Finance 29, 449-470.

Moskowitz, Tobias J., and Mark Grinblatt, 1999, Do industries explain momentum?, The Journal of Finance 54, 1249-1290.

Moskowitz, Tobias J., Yoa Hua Ooi, and Lasse H. Pedersen, 2012, Time series momentum, Journal of Financial Economics 104, 228-250.

Okunev, John, and Derek White, 2003, Do momentum-based strategies still work in foreign currency markets?, Journal of Financial and Quantitative Analysis 38, 425-447.

Rouwenhorst, K. Geert, 1998, International momentum strategies, Journal of Finance 53, $267-284$.

— 1999, Local return factors and turnover in emerging stock markets, Journal of Finance 54, 1439-1464.

Stivers, Chris, and Licheng Sun, 2010, Cross-sectional return dispersion and time-variation in value and momentum premia, Journal of Financial and Quantitative Analysis 45, 987-1014.

Sunstein, Cass R., and Richard Zeckhauser, 2008, Overreaction to fearsome risks, Harvard University Working Paper. 